Check for updates

Cite this: RSC Adv., 2018, 8, 33728

\title{
Structure and reducibility of yttrium-doped cerium dioxide nanoparticles and (111) surface $\uparrow$
}

Received 21st August 2018

Accepted 11th September 2018

DOI: $10.1039 / \mathrm{c} 8 \mathrm{ra07014h}$

rsc.li/rsc-advances

\author{
Hristiyan A. Aleksandrov, (D) *ab Iskra Z. Koleva, ${ }^{a}$ Konstantin M. Neyman, (D) bc \\ Tatyana T. Tabakova (D) ${ }^{d}$ and Georgi N. Vayssilov (D) *a
}

\section{Introduction}

In recent years, ceria-based materials have excited tremendous interest from both fundamental scientific and commercial points of view. In particular, ceria has attracted much attention because of its crucial role as a component of catalysts for numerous catalytic applications. The ever-growing interest is demonstrated by the vast numbers of publications starting from the review by Trovarelli in 1996, ${ }^{1}$ which was followed by two books in 2002 (ref. 2) and 2013 (ref. 3) and many reviews, ${ }^{4-6}$ as well as a special issue of Catalysis Today in $2015 .^{7}$

Many studies have revealed the applicability of ceria as a support in different catalysts owing to its well-known high oxygen storage capacity (OSC). ${ }^{1-3}$ It is a reducible oxide, and $\mathrm{O}$ vacancies can be created in ceria at elevated temperatures. This process is accompanied by the reduction of two $\mathrm{Ce}^{4+}$ cations to the $\mathrm{Ce}^{3+}$ state for each $\mathrm{O}$ vacancy and can be reversible depending on the conditions. ${ }^{1-4}$

${ }^{a}$ Faculty of Chemistry and Pharmacy, University of Sofia, 1126 Sofia, Bulgaria ${ }^{b}$ Departament de Ciència de Materials i Quimica Física and Institut de Quimica Teòrica i Computacional, Universitat de Barcelona, 08028 Barcelona, Spain 'ICREA (Institució Catalana de Recerca i Estudis Avançats), 08010 Barcelona, Spain ${ }^{d}$ Institute of Catalysis, Bulgarian Academy of Sciences, Acad. G. Bonchev Str., bl. 11, Sofia 1113, Bulgaria.E-mail: haa@chem.uni-sofia.bg

$\uparrow$ Electronic supplementary information (ESI) available. See DOI: $10.1039 / \mathrm{c} 8 \mathrm{ra} 07014 \mathrm{~h}$
Doping of ceria is a commonly exploited approach for tailoring its redox properties and concomitantly affecting its catalytic behavior. ${ }^{8}$ The presence of aliovalent dopants ${ }^{9}$ causes the appearance of extrinsic defects that play a key role in the performance of many catalytic processes. Of particular importance for both technological applications and fundamental research are $\mathrm{CeO}_{2}$ materials doped with rare-earth elements, including yttrium. When $\mathrm{CeO}_{2}$ is doped by an oxide of a trivalent metal, such as $\mathrm{Y}_{2} \mathrm{O}_{3}$, the initial structure contains $\mathrm{O}$ vacancies that are created in order to compensate the effective negative charge produced by the substitution of $\mathrm{Ce}^{4+}$ with $\mathrm{Y}^{3+}$. Thus, a distortion is induced in the cubic matrix of the resulting $\mathrm{Y}_{2} \mathrm{O}_{3}-\mathrm{CeO}_{2}$ mixed oxide. The beneficial effect of yttrium doping on the activity of ceria in soot combustion has been demonstrated by Atribak et al. ${ }^{10}$ Considering the abundance of yttrium resources, She $e t$ al. studied the effect of the addition of $\mathrm{Y}(0-5 \mathrm{wt} \%)$ to a $\mathrm{CuO} / \mathrm{CeO}_{2}$ catalyst on its activity in the water-gas shift. ${ }^{11}$ The highest catalytic activity was exhibited by the catalyst doped with $2 \mathrm{wt} \% \mathrm{Y}$. The effects of different synthesis routes for the preparation of Y-doped ceria and of various amounts of $\mathrm{Y}$ on the performance of the preferential oxidation of CO (PROX) in the presence of excess hydrogen on supported gold catalysts have been discussed by Ilieva et al. ${ }^{12}$ Irrespective of the preparation method, very similar degrees of conversion of $\mathrm{CO}$ were recorded for samples containing 1-5 wt $\% \mathrm{Y}_{2} \mathrm{O}_{3}$ in the temperature range of $80-$ 
$120{ }^{\circ} \mathrm{C}$, which is of interest for the operation of fuel cells. The relatively low activity that was observed for doped ceria samples with a $\mathrm{Y}_{2} \mathrm{O}_{3}$ content of $7.5 \mathrm{wt} \%$ was attributed to the restricted supply of oxygen due to the assumed ordering of surface oxygen vacancies around segregated $\mathrm{Y}^{3+}$. Similarly, no improvement in the PROX activity and stability of gold catalysts supported on Y-doped ceria was reported by Jardim et al.,${ }^{13}$ who explained this result by the surface segregation of the large amount of $\mathrm{Y}_{2} \mathrm{O}_{3}$ used (30 wt $\%$ ).

Several theoretical investigations have focused on the understanding of the doping of ceria by yttrium and lanthanide metals. For instance, Dholabhai et al. studied the formation and migration of oxygen vacancies in Pr- and Gddoped ceria with the help of methods based on density functional theory (DFT). ${ }^{\mathbf{1 4 1} 15}$ The local ordering of oxygen vacancies in $\mathrm{Ce}_{1-x} \mathrm{Y}_{x} \mathrm{O}_{2-x / 2}$ where $x=0.04,0.08,0.11,0.18$, and 0.26 (corresponding to 2, 4, 6, 10, and $15 \mathrm{~mol}_{\%} \mathrm{Y}_{2} \mathrm{O}_{3}$ ) has been investigated by analyzing data from experimental measurements (impedance spectroscopy and neutron diffraction) and ab initio molecular dynamics simulations. ${ }^{\mathbf{1 6}}$ It was concluded that the ionic conductivity of Y-doped ceria decreased with an increase in the amount of $\mathrm{Y}_{2} \mathrm{O}_{3}$ because of ordering of anion vacancies. The distribution of rare-earth oxide dopants in ceria and the oxygen ion conductivity of these systems were also investigated by Grieshammer et al., who combined DFT and Monte Carlo studies. ${ }^{17} \mathrm{Hu}$ and Metiu $^{18}$ modelled the doping of the ceria(111) surface by a single $\mathrm{Y}^{3+}$ cation with no charge-compensating $\mathrm{O}$ vacancy, which would require the introduction of a second dopant cation. This single dopant lowered the formation energy of an $\mathrm{O}$ vacancy by more than $1.2 \mathrm{eV}$. Surprisingly, in another DFT-based study of an yttrium-doped $\mathrm{CeO}_{2}(110)$ surface ${ }^{19}$ it was reported that a peculiar arrangement of the charge distribution in the form of a structure comprising two $\mathrm{Y}^{3+}$ cations, one $\mathrm{O}$ vacancy, one $\mathrm{Ce}^{3+}$ cation and one $\mathrm{O}^{-}$anion was found. This charge distribution was reported to be the most stable but did not provide the energetics of the conventional arrangement containing only $\mathrm{Ce}^{4+}$ and $\mathrm{O}^{2-}$ ions. In any case, it will be interesting for catalytic applications and further studies to understand the influence of $\mathrm{Y}^{3+}$ cations on the reducibility of stoichiometric $\mathrm{CeO}_{2} / \mathrm{Y}_{2} \mathrm{O}_{3}$ systems and to clarify whether nanostructuring changes the behavior of these systems with respect to the surface models.

In the current study, we modeled various structures in which $\mathrm{Y}^{3+}$ cations replace $\mathrm{Ce}^{4+}$ cations on/in the $\mathrm{CeO}_{2}(111)$ slab and two models of ceria nanoparticles with different sizes $\left(\mathrm{Ce}_{21} \mathrm{O}_{42}\right.$ and $\left.\mathrm{Ce}_{40} \mathrm{O}_{80}\right)$ with low $\mathrm{Y}$ : Ce atomic ratios of $3.9 \%$ / $8.0 \%$ for the slab model and $10.5 \% / 23.5 \%$ and $5.3 \% / 11.1 \%$ for the two nanoparticle models, respectively. The goals of the present study were to clarify whether yttrium dopants prefer to segregate or be distantly distributed among cerium cations and to estimate changes in the reducibility of ceria in the presence of $\mathrm{Y}^{3+}$ cations. It is also interesting to observe the differences between the behavior of the slab, which can represent larger particles, and the nanoparticle models, where irregularities and low-coordinated surface positions (edges and corners) are more abundant.

\section{Computational details and models}

The calculations were performed using a periodic plane-wave DFT method with the PW91 (ref. 20) exchange-correlation functional of the generalized gradient approximation (GGA) type as implemented in the VASP program. ${ }^{21-23}$ Stoichiometric and reduced ceria were described within the so-called GGA+U approach, ${ }^{24,25}$ in which an on-site coulombic interaction with $U=4 \mathrm{eV}$ (ref. 26) was included. Our test calculations without applying the $\mathrm{U}$ correction for systems that do not contain $\mathrm{Ce}^{3+}$ cations showed that the relative stability of the structures remains similar to that determined with $U=4 \mathrm{eV}$. A plane-wave basis set with a cut-off of $415 \mathrm{eV}$ for the kinetic energy and the projector-augmented wave $\mathrm{e}^{23}$ description of core-valence electron interactions were employed. During geometry optimization all atoms were allowed to relax locally until the maximum forces that acted on each atom became less than $0.02 \mathrm{eV} \AA^{-1}$. We performed only $\Gamma$-point calculations. Spin polarization was taken into account when $\mathrm{O}$ vacancies were modeled because this leads to the formation of $\mathrm{Ce}^{3+}$ cations, which have unpaired electrons. The formation energy of an oxygen vacancy $E_{\mathrm{vac}}$ was calculated with respect to half the energy of an $\mathrm{O}_{2}$ molecule in its triplet state as follows:

$$
\begin{gathered}
E_{\mathrm{vac}}=E\left(\mathrm{Ce}_{x} \mathrm{O}_{2 x-1}\right)+1 / 2 \times E\left(\mathrm{O}_{2}\right)-E\left(\mathrm{Ce}_{x} \mathrm{O}_{2 x}\right) \\
E_{\mathrm{vac}}=E\left(\mathrm{Ce}_{x-2} \mathrm{Y}_{2} \mathrm{O}_{2 x-2}\right)+1 / 2 \times E\left(\mathrm{O}_{2}\right)-E\left(\mathrm{Ce}_{x-2} \mathrm{Y}_{2} \mathrm{O}_{2 x-1}\right)
\end{gathered}
$$

\section{1 $\mathrm{CeO}_{2}(111)$ surface slab model}

The $\mathrm{CeO}_{2}(111)$ surface was modelled with a $\mathrm{Ce}_{54} \mathrm{O}_{108}$ slab comprising three $\mathrm{CeO}_{2}$ (nine atomic) layers and a $3 \times 6$ surface cell with cell parameters of $a=13.224 \AA$, $b=19.836 \AA, c=$ $19.353 \AA$, $\alpha=\beta=90^{\circ}$, and $\gamma=60^{\circ}$. The lateral dimensions of the cell were fixed according to the experimental bulk geometry $(a=541 \mathrm{pm}) .{ }^{27}$ The notation used for the modelled structures is given in the sections below, where the corresponding structures are discussed.

\section{$2.2 \mathrm{Ce}_{21} \mathrm{O}_{42}$ and $\mathrm{Ce}_{40} \mathrm{O}_{80}$ nanoparticle models}

We employed a small $\mathrm{Ce}_{21} \mathrm{O}_{42}$ ceria nanoparticle with a diameter of about $1 \mathrm{~nm},,^{\mathbf{2 8 - 3 4}}$ which was located in a cubic unit cell with dimensions of $2.0 \times 2.0 \times 2.0 \mathrm{~nm}$, as well as a larger $\mathrm{Ce}_{40} \mathrm{O}_{80}$ nanoparticle with a diameter of about $1.5 \mathrm{~nm},{ }^{30,35-38}$ which was positioned in a unit cell with a rectangular parallelepiped shape and dimensions of $2.2 \times 1.9 \times 1.9 \mathrm{~nm}$. In these models, the distance between neighboring images in the periodic unit cells is at least $0.9 \mathrm{~nm}$. The notation used for the modelled structures is given in the sections below, where the corresponding structures are discussed.

\section{Results and discussion}

\subsection{Yttrium-doped $\mathrm{CeO}_{2}(111)$ surface}

For the regular $\mathrm{CeO}_{2}$ (111) surface, we modeled various structures of two types of stoichiometric system in which two and 
four cerium ions, respectively, were substituted by yttrium ions. In addition, for the former type of model we computed the formation energies of an oxygen vacancy.

3.1.1 Stoichiometric systems containing two yttrium ions. We modeled 27 structures in which two $\mathrm{Y}^{3+}$ cations replace two $\mathrm{Ce}^{4+}$ cations. In order to balance the charge on the system, one $\mathrm{O}$ atom was removed from the structure shown in Fig. 1 (see also Table 1). We considered structures in which an $\mathrm{O}$ vacancy was created in three different positions: (i) in the surface layer (SL, $\mathrm{O}_{\mathrm{SL}}$ ); (ii) in the first subsurface layer $\left(\mathrm{FS}, \mathrm{O}_{\mathrm{FS}}\right.$ ); and (iii) in the second subsurface layer $\left(\mathrm{SS}, \mathrm{O}_{\mathrm{SS}}\right)$. The positions of cerium cations replaced by $\mathrm{Y}^{3+}$ cations are specified in Fig. 1 . To denote the resulting structures, the position of the created $\mathrm{O}$ vacancy is followed (in parentheses) by the positions of the replaced $\mathrm{Ce}^{4+}$ ions.

The stability of the modeled structures (Table 1 ) depends on the positions of both the two yttrium centers and the $\mathrm{O}$ vacancy and varies by up to $1.0 \mathrm{eV}$. The three most stable and essentially isoenergetic structures, namely, $\mathrm{O}_{\mathrm{FS}}(1 \mathrm{~B}, 2 \mathrm{C}), \mathrm{O}_{\mathrm{FS}}(2 \mathrm{C}, 2 \mathrm{D})$ and $\mathrm{O}_{\mathrm{SS}}(2 \mathrm{C}, 2 \mathrm{D})$, contain at least one subsurface $\mathrm{Y}^{3+}$ cation, and the $\mathrm{O}$ vacancy is in either the subsurface or the second subsurface layer. The next two structures, namely, $\mathrm{O}_{\mathrm{FS}}(1 \mathrm{~A}, 1 \mathrm{~B})$ and
$\mathrm{O}_{\mathrm{SL}}(1 \mathrm{~A}, 1 \mathrm{~B})$, in which both yttrium cations are on the surface, are less stable by $c a$. $0.3 \mathrm{eV}$. In all the most stable structures destabilized by up to $0.5 \mathrm{eV}$ the two $\mathrm{Y}^{3+}$ cations are located at neighboring sites separated by up to $c a .420 \mathrm{pm}$. Note, however, that there are structures that completely or partially have the above features but are notably less stable (see the brown triangles in Fig. 2A). Fig. 2B (brown triangles), which includes all the modeled relative locations of the yttrium centers, also shows the lack of a clear relation between the relative stability and the location of the two dopant cations on the surface, in the subsurface layer or in both positions.

Although the $\mathrm{O}$ vacancies in the most stable structures are located at sites that neighbor yttrium centers, a general correlation between the $\mathrm{Y}-\mathrm{O}_{\text {vac }}$ distances (accounted for in different ways, see Fig. S4 in ESI $\dagger$ ) and the relative stability of all the modeled structures cannot be found.

In order to determine whether the space of the missing $\mathrm{O}$ atom can be refilled by an $\mathrm{O}$ atom, we modeled structures in which an added $\mathrm{O}$ atom was put in the position of the missing $\mathrm{O}$ atom in the Y-containing models discussed above. The systems were optimized to be spin-polarized and neutral. All the structures with an additional $\mathrm{O}$ atom were calculated to be less stable
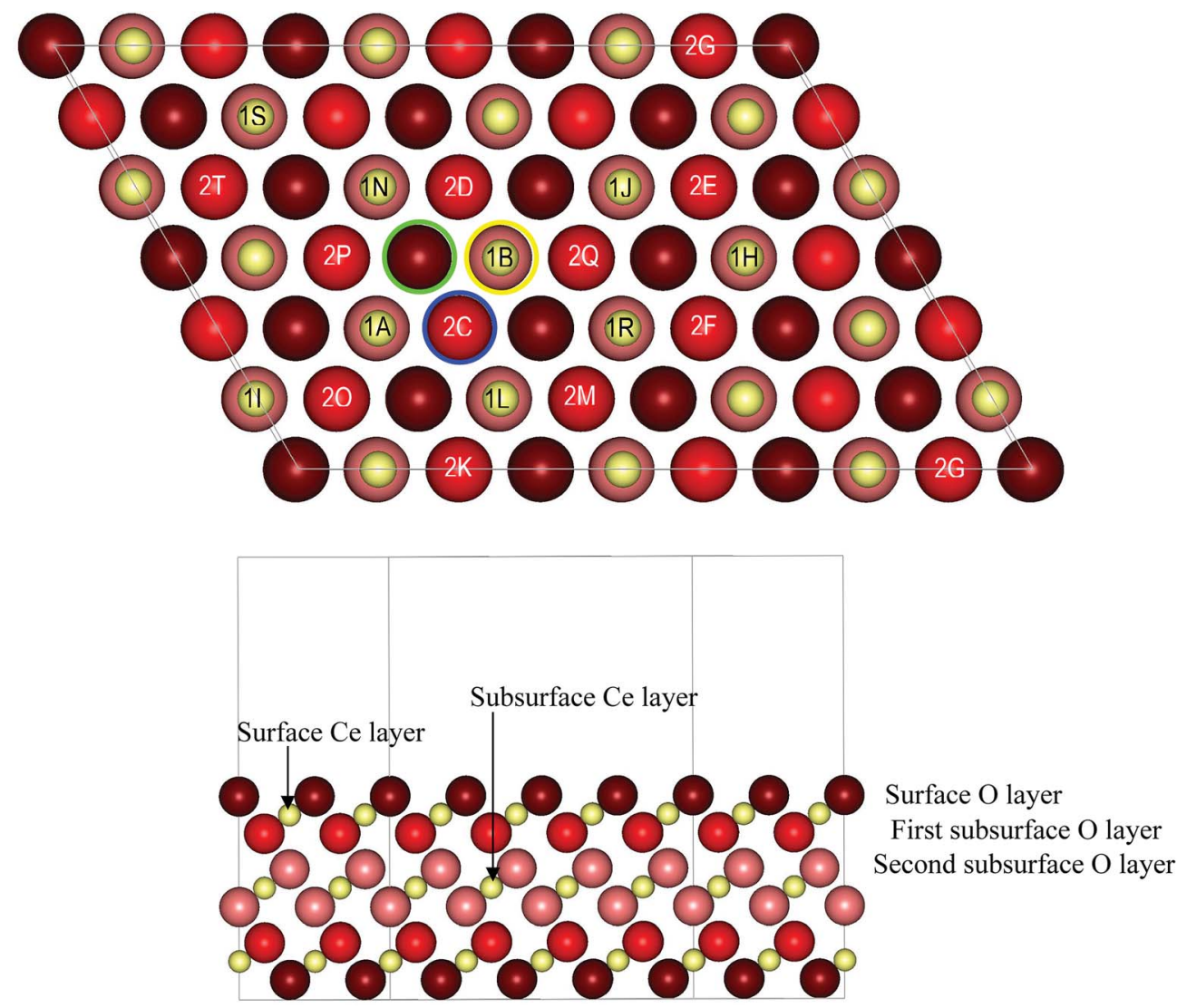

Fig. 1 Top (upper panel) and side (lower panel) views of $\mathrm{CeO}_{2}(111)$ surface slab model displaying one unit cell. Each position where a Ce cation is replaced by a $\mathrm{Y}^{3+}$ cation is denoted by a number and a capital letter. The number indicates the vertical position of the Ce cation: $1-$ in the first (surface) cationic layer and 2 - in the second (subsurface) cationic layer, which is not shown in the upper panel, i.e., below an $O$ anion in the first subsurface anionic layer. Capital letters are used to distinguish various surface and subsurface positions. An $O$ vacancy created in the surface $O$ layer or in the first or second subsurface O layers is marked by a green, blue or yellow circle, respectively. Color coding: Ce - yellow, O in the surface layer - dark red, $\mathrm{O}$ in the first subsurface layer - red, $\mathrm{O}$ in the second subsurface layer (located exactly below a surface Ce atom) - light red. 
Table 1 Energetic (in eV), structural (in pm) and coordination characteristics of the modeled $\mathrm{CeO}_{2}(111)$ structures containing two $\mathrm{Y}^{3+}$ cations and one $O$ vacancy either in the surface $\left(\mathrm{O}_{\mathrm{SL}}\right)$, first subsurface $\left(\mathrm{O}_{\mathrm{FS}}\right)$ or second subsurface $\left(\mathrm{O}_{\mathrm{SS}}\right)$ layer

\begin{tabular}{llllll}
\hline Structure $^{a}$ & $E_{\text {rel }}^{b}$ & $\mathrm{Y}^{b} \mathrm{Y}^{c}$ & ${\mathrm{Y}-\mathrm{O}_{\text {vac }}{ }^{d}}$ & $\mathrm{~N}^{e}$ & $\mathrm{M}^{f}$ \\
\hline$O_{S L}(1 \mathrm{~A}, 1 B)$ & 0.32 & 421 & 260,263 & 6,6 & 1 \\
$O_{S L}(1 B, 2 C)$ & 0.33 & 384 & 263,456 & 6,8 & 2 \\
$O_{S L}(2 C, 2 D)$ & 0.40 & 375 & 458,460 & 8,8 & 2 \\
$O_{S L}(2 E, 2 F)$ & 0.67 & 378 & 893,894 & 8,8 & 2 \\
$O_{S L}(2 E, 2 G)$ & 0.68 & 376 & 895,1041 & 8,8 & 2 \\
$O_{S L}(1 H, 2 G)$ & 0.79 & 662 & 890,1042 & 7,8 & 0 \\
$O_{S L}(2 F, 1 H)$ & 0.83 & 381 & 889,893 & 8,7 & 2 \\
$O_{S L}(1 I, 1 J)$ & 0.86 & 1137 & 596,609 & 7,7 & 0 \\
$O_{S L}(1 H, 1 J)$ & 1.00 & 375 & 600,887 & 7,7 & 2 \\
$O_{F S}(1 B, 2 C)$ & 0.00 & 410 & 252,256 & 6,7 & 1 \\
$O_{F S}(2 C, 2 D)$ & 0.02 & 378 & 257,448 & 7,8 & 2 \\
$O_{F S}(1 A, 1 B)$ & 0.26 & 409 & 250,253 & 6,6 & 1 \\
$O_{F S}(2 E, 2 F)$ & 0.37 & 378 & 706,801 & 8,8 & 2 \\
$O_{F S}(2 E, 2 G)$ & 0.40 & 378 & 803,1038 & 8,8 & 2 \\
$\mathrm{O}_{\mathrm{FS}}(1 \mathrm{H}, 2 \mathrm{G})$ & 0.51 & 661 & 799,801 & 7,8 & 0 \\
$O_{F S}(2 F, 1 H)$ & 0.52 & 380 & 706,800 & 8,7 & 2 \\
$\mathrm{O}_{\mathrm{FS}}(1 \mathrm{I}, 1 \mathrm{~J})$ & 0.63 & 1156 & 591,596 & 7,7 & 0 \\
$O_{F S}(1 H, 1 J)$ & 0.73 & 376 & 595,799 & 7,7 & 2 \\
$O_{S S}(2 C, 2 D)$ & 0.02 & 406 & 249,252 & 7,7 & 1 \\
$O_{S S}(1 B, 2 C)$ & 0.38 & 420 & 249,265 & 6,7 & 1 \\
$O_{S S}(2 E, 2 F)$ & 0.49 & 379 & 593,594 & 8,8 & 2 \\
$O_{S S}(2 E, 2 G)$ & 0.55 & 376 & 595,798 & 8,8 & 2 \\
$O_{S S}(2 F, 1 H)$ & 0.72 & 377 & 593,701 & 8,7 & 2 \\
$\mathrm{O}_{S S}(1 \mathrm{H}, 2 \mathrm{G})$ & 0.73 & 660 & 703,799 & 7,8 & 0 \\
$O_{S S}(1 A, 1 B)$ & 0.83 & 377 & 266,442 & 7,6 & 2 \\
$\mathrm{O}_{\mathrm{SS}}(1 \mathrm{I}, 1 \mathrm{~J})$ & 0.91 & 1147 & 448,797 & 7,7 & 0 \\
$O_{S S}(1 H, 1 J)$ & 0.93 & 381 & 448,700 & 7,7 & 2 \\
$a$ & & & & &
\end{tabular}

${ }^{a}$ Position of $\mathrm{Y}^{3+}$ cations as shown in Fig. 1. Structure names in italics indicate that the $\mathrm{Y}^{3+}$ cations are located in nearest-neighboring positions. ${ }^{b}$ Relative energy with respect to the most stable structure, i.e., $\mathrm{O}_{\mathrm{FS}}(1 \mathrm{~B}, 2 \mathrm{C}) .{ }^{c}$ Distance between two nearest-neighboring $\mathrm{Y}$ cations. ${ }^{d}$ Distances between $\mathrm{Y}$ atoms and the $\mathrm{O}$ vacancy. Coordination numbers of $\mathrm{Y}^{3+}$ with respect to $\mathrm{O}$ atoms. ${ }^{f}$ Number of $\mathrm{O}$ atoms bound simultaneously to both $\mathrm{Y}^{3+}$ cations.

by $0.83,1.27$ and $1.12 \mathrm{eV}$ than the initial structures, namely, $\mathrm{O}_{\mathrm{SL}}(1 \mathrm{~A}, 1 \mathrm{~B}), \mathrm{O}_{\mathrm{FS}}(1 \mathrm{~B}, 2 \mathrm{C})$ and $\mathrm{O}_{\mathrm{SS}}(2 \mathrm{C}, 2 \mathrm{D})$, plus half a gas-phase $\mathrm{O}_{2}$ molecule, respectively. Hence, the filling by an oxygen atom of the charge-compensating $\mathrm{O}$ vacancy in such surface and subsurface positions is, not unexpectedly, energetically unfavorable up to rather high oxygen pressures.

In order to determine the relative stability of the electronic states of a system reported elsewhere, ${ }^{19}$ we performed geometry optimization of the $\mathrm{O}_{\mathrm{SL}}(1 \mathrm{I}, 1 \mathrm{~J})$ and $\mathrm{O}_{\mathrm{SL}}(1 \mathrm{~B}, 2 \mathrm{C})$ structures in the fixed triplet state. In this way, we obtained structures with an electron density distribution analogous to that in ref. 19, with one $\mathrm{Ce}^{3+}$ cation and partially electron-deficient oxygen anions due to the forced transfer of one $\mathrm{O} 2 \mathrm{p}$ electron to a $\mathrm{Ce}^{4+}$ cation. However, in the cases of both $\mathrm{O}_{\mathrm{SL}}(1 \mathrm{I}, 1 \mathrm{~J})$ and $\mathrm{O}_{\mathrm{SL}}(1 \mathrm{~B}, 2 \mathrm{C})$ this triplet state was less stable by more than $1.4 \mathrm{eV}$ than the aforementioned singlet state. Hence, the spontaneous transfer of an electron from an $\mathrm{O}^{2-}$ ion to a $\mathrm{Ce}^{4+}$ ion in the yttriumdoped ceria systems appears to result in an excited state rather than the ground state.

3.1.2 Oxygen vacancy in systems containing two yttrium ions. In order to estimate the reducibility of ceria in the
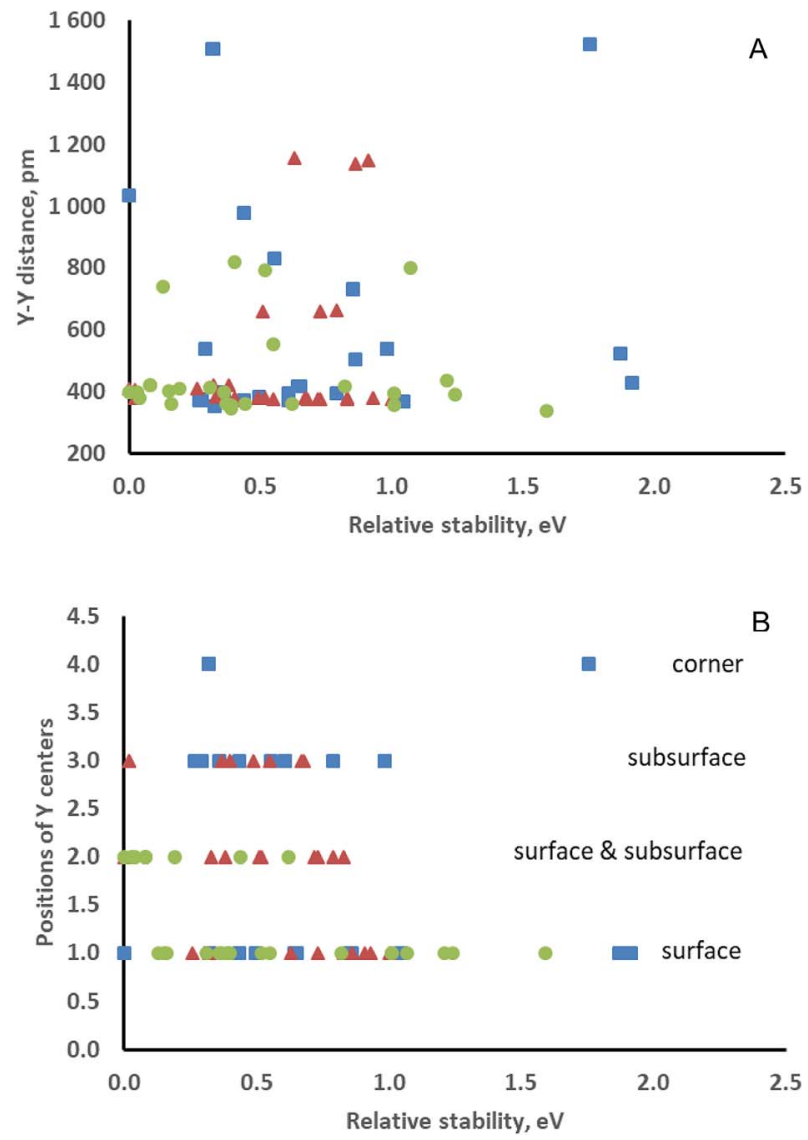

Fig. 2 Relations between the relative stability of the various calculated models and the nearest $Y-Y$ distances $(A)$ or the positions occupied by the two $Y$ centers (B). Ceria surface - brown triangles, smaller nanoparticles - green bullets and larger nanoparticles - blue squares.

presence of two $\mathrm{Y}^{3+}$ cations, we modeled the creation of an oxygen vacancy in the most stable structures in which the oxygen vacancy was located in the surface layer, i.e., $\mathrm{O}_{\mathrm{SL}}(1 \mathrm{~A}, 1 \mathrm{~B})$, first subsurface layer, i.e., $\mathrm{O}_{\mathrm{FS}}(1 \mathrm{~B}, 2 \mathrm{C})$, and second subsurface layer, i.e., $\mathrm{O}_{\mathrm{ss}}(2 \mathrm{C}, 2 \mathrm{D})$. The $\mathrm{O}$ center was removed from various surface, subsurface and second subsurface (below surface Ce or Y) positions (see Fig. 3 and Table 2). In most cases, the locations of the two $\mathrm{Ce}^{4+}$ cations that were reduced to $\mathrm{Ce}^{3+}$ were calculated to be nearby the created $\mathrm{O}$ vacancy. We note in passing that both the nearest-neighbor and the next-nearest-neighbor locations of the two $\mathrm{Ce}^{3+}$ cations with respect to the $\mathrm{O}$ vacancies resulted from DFT-based calculations for slab models of pristine ceria surfaces. ${ }^{39,40}$

As a reference, we considered the formation of an oxygen vacancy on the surface and in the first and second subsurface layers of the undoped surface (Fig. 1). The most stable structure is that in which the $\mathrm{O}$ vacancy is in the first subsurface layer, for which $E_{\mathrm{vac}}=2.55 \mathrm{eV}$, which is close to the value of $2.48 \mathrm{eV}$ from PW91+4 calculations. ${ }^{40}$ The structures with the vacancy in the second subsurface layer or surface layer are higher in energy by 0.22 and $0.33 \mathrm{eV}$, respectively.

The lowest formation energy of an $\mathrm{O}$ vacancy among the $\mathrm{Y}$ doped structures corresponds to $\mathrm{O}_{\mathrm{FS}}(1 \mathrm{~B}, 2 \mathrm{C})-2 \mathrm{f}$, in which both 

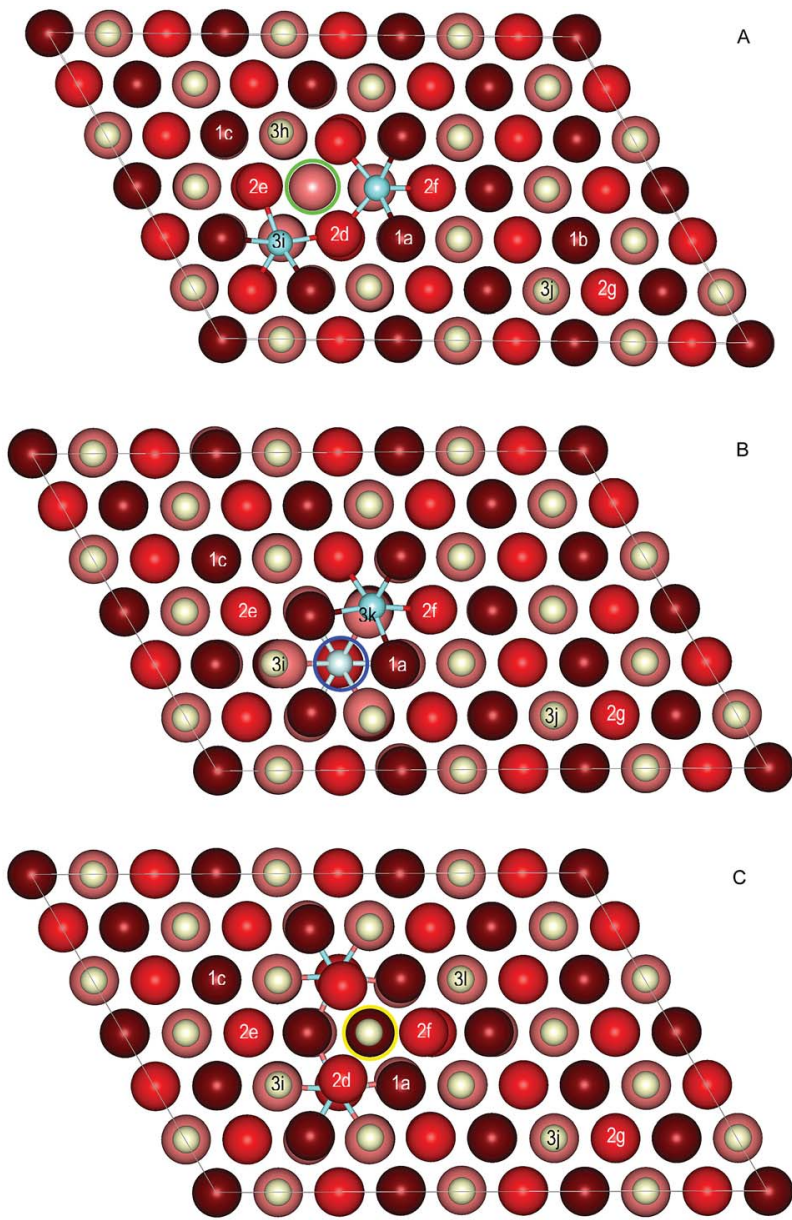

Fig. 3 Top view of the initial structures of the doped ceria surface used to model the formation of a second oxygen vacancy: A $\mathrm{O}_{S \mathrm{~L}}(1 \mathrm{~A}, 1 \mathrm{~B})$ structure, $\mathrm{B}-\mathrm{O}_{\mathrm{FS}}(1 \mathrm{~B}, 2 \mathrm{C})$ structure, and $\mathrm{C}-\mathrm{O}_{\mathrm{SS}}(2 \mathrm{C}, 2 \mathrm{D})$ structure. The first $O$ vacancy is marked as a green, blue or yellow circle; see the caption of Fig. 1. Each position of the second removed $O$ atom is denoted by a number and a lower-case letter. The number indicates the vertical position of the removed $O$ atom: 1 - from the first (surface) anionic layer, 2 - from the second (subsurface) anionic layer and 3 - from the third (directly below a surface cation) anionic layer Lower-case letters are used to distinguish various surface and subsurface positions. Color coding: $\mathrm{Ce}$ - yellow, $\mathrm{O}$ in the surface layer - dark red, $O$ in the first subsurface layer - red, $O$ in the second subsurface layer - light red, $\mathrm{Y}$ - light blue. For clarity the $\mathrm{Y}-\mathrm{O}$ bonds are shown.

missing $\mathrm{O}$ atoms are in the first subsurface layer with $E_{\mathrm{vac}}=$ $2.52 \mathrm{eV}$, which is only slightly lower than the value calculated for the pristine $\mathrm{CeO}_{2}$ (111) surface. The next four structures have $E_{\text {vac }}$ values that are higher by $0.1-0.2 \mathrm{eV}$ and feature $\mathrm{O}$ vacancies in different locations - a combination of the surface and first and second subsurface layers. This similarity in the stability of structures with the $\mathrm{O}$ vacancy in different locations suggests that various spatial distributions of $\mathrm{O}$ vacancies may exist in $\mathrm{Y}$ doped ceria. One should note the $\mathrm{O}_{\mathrm{SL}}(1 \mathrm{~A}, 1 \mathrm{~B})-1 \mathrm{a}$ structure, for which $E_{\mathrm{vac}}=2.61 \mathrm{eV}$, where both $\mathrm{O}$ vacancies are on the surface. This value is lower by $0.27 \mathrm{eV}$ than the $E_{\mathrm{vac}}$ calculated for the removal of an equivalent surface $\mathrm{O}$ atom from the pristine $\mathrm{CeO}_{2}(111)$ surface. This result implies that the presence of $\mathrm{Y}^{3+}$
Table 2 Energetic (in eV) and structural (in pm) characteristics of the modeled $\mathrm{Y}$-doped $\mathrm{CeO}_{2}(111)$ surface structures containing two $\mathrm{Y}$ cations and two $O$ vacancies

\begin{tabular}{|c|c|c|c|c|}
\hline Structure $^{a}$ & $E_{\mathrm{rel}}^{b}$ & $E_{\mathrm{vac}}^{c}$ & $\mathrm{O}_{\mathrm{vac}}-\mathrm{O}_{\mathrm{vac}}{ }^{d}$ & $\# \mathrm{Ce}^{e}$ \\
\hline $\mathrm{O}_{\mathrm{SL}}(1 \mathrm{~A}, 1 \mathrm{~B})-1 \mathrm{a}$ & 0.41 & 2.61 & 389 & 39,40 \\
\hline $\mathrm{O}_{\mathrm{SL}}(1 \mathrm{~A}, 1 \mathrm{~B})-2 \mathrm{~g}$ & 0.55 & 2.75 & 1179 & 13,48 \\
\hline $\mathrm{O}_{\mathrm{SL}}(1 \mathrm{~A}, 1 \mathrm{~B})-1 \mathrm{~b}$ & 0.60 & 2.80 & 656 & 47,48 \\
\hline $\mathrm{O}_{\mathrm{SL}}(1 \mathrm{~A}, 1 \mathrm{~B})-1 \mathrm{c}$ & 0.60 & 2.80 & 389 & 15,16 \\
\hline $\mathrm{O}_{\mathrm{SL}}(1 \mathrm{~A}, 1 \mathrm{~B})-3 \mathrm{j}$ & 0.63 & 2.83 & 1014 & 47,48 \\
\hline $\mathrm{O}_{\mathrm{SL}}(1 \mathrm{~A}, 1 \mathrm{~B})-2 \mathrm{f}$ & 0.75 & 2.94 & 482 & 27,31 \\
\hline $\mathrm{O}_{\mathrm{SL}}(1 \mathrm{~A}, 1 \mathrm{~B})-3 \mathrm{~h}$ & 0.90 & 3.10 & 388 & 16,20 \\
\hline $\mathrm{O}_{\mathrm{SL}}(1 \mathrm{~A}, 1 \mathrm{~B})-2 \mathrm{e}$ & 0.92 & 3.12 & 242 & 15,16 \\
\hline $\mathrm{O}_{\mathrm{SL}}(1 \mathrm{~A}, 1 \mathrm{~B})-2 \mathrm{~d}$ & 1.02 & 3.21 & 233 & 31,40 \\
\hline $\mathrm{O}_{\mathrm{SL}}(1 \mathrm{~A}, 1 \mathrm{~B})-3 \mathrm{i}$ & 1.05 & 3.25 & 386 & 20,31 \\
\hline$O_{F S}(1 B, 2 C)-2 f$ & 0.00 & 2.52 & 391 & 27,39 \\
\hline $\mathrm{O}_{\mathrm{FS}}(1 \mathrm{~B}, 2 \mathrm{C})-1 \mathrm{c}$ & 0.14 & 2.65 & 606 & 6,16 \\
\hline $\mathrm{O}_{\mathrm{FS}}(1 \mathrm{~B}, 2 \mathrm{C})-2 \mathrm{e}$ & 0.15 & 2.67 & 388 & 4,16 \\
\hline $\mathrm{O}_{\mathrm{FS}}(1 \mathrm{~B}, 2 \mathrm{C})-1 \mathrm{a}$ & 0.25 & 2.76 & 247 & 39,40 \\
\hline $\mathrm{O}_{\mathrm{FS}}(1 \mathrm{~B}, 2 \mathrm{C})-3 \mathrm{j}$ & 0.29 & 2.80 & 811 & 47,48 \\
\hline $\mathrm{O}_{\mathrm{FS}}(1 \mathrm{~B}, 2 \mathrm{C})-2 \mathrm{~g}$ & 0.30 & 2.82 & 1009 & 13,47 \\
\hline $\mathrm{O}_{\mathrm{FS}}(1 \mathrm{~B}, 2 \mathrm{C})-3 \mathrm{k}$ & 0.72 & 3.24 & 255 & 1,30 \\
\hline $\mathrm{O}_{\mathrm{FS}}(1 \mathrm{~B}, 2 \mathrm{C})-3 \mathrm{i}$ & 0.76 & 3.28 & 248 & 4,32 \\
\hline $\mathrm{O}_{\mathrm{Ss}}(2 \mathrm{C}, 2 \mathrm{D})-2 \mathrm{~g}$ & 0.10 & 2.61 & 974 & 13,48 \\
\hline $\mathrm{O}_{\mathrm{SS}}(2 \mathrm{C}, 2 \mathrm{D})-1 \mathrm{c}$ & 0.18 & 2.70 & 662 & 6,15 \\
\hline $\mathrm{O}_{\mathrm{ss}}(2 \mathrm{C}, 2 \mathrm{D})-2 \mathrm{e}$ & 0.23 & 2.75 & 463 & 4,16 \\
\hline $\mathrm{O}_{\mathrm{ss}}(2 \mathrm{C}, 2 \mathrm{D})-3 \mathrm{i}$ & 0.38 & 2.90 & 385 & 4,20 \\
\hline $\mathrm{O}_{\mathrm{Ss}}(2 \mathrm{C}, 2 \mathrm{D})-3 \mathrm{j}$ & 0.45 & 2.97 & 764 & 42,48 \\
\hline $\mathrm{O}_{\mathrm{SS}}(2 \mathrm{C}, 2 \mathrm{D})-3 \mathrm{l}$ & 0.47 & 2.98 & 386 & 18,27 \\
\hline $\mathrm{O}_{\mathrm{ss}}(2 \mathrm{C}, 2 \mathrm{D})-2 \mathrm{~d}$ & 0.53 & 3.05 & 241 & 3,4 \\
\hline $\mathrm{O}_{\mathrm{ss}}(2 \mathrm{C}, 2 \mathrm{D})-1 \mathrm{a}$ & 0.53 & 3.05 & 397 & 39,40 \\
\hline $\mathrm{O}_{\mathrm{SS}}(2 \mathrm{C}, 2 \mathrm{D})-2 \mathrm{f}$ & 0.71 & 3.23 & 243 & 26,27 \\
\hline $\mathrm{O}_{\mathrm{SS}}(2 \mathrm{C}, 2 \mathrm{D})-4 \mathrm{a}$ & 0.78 & 3.30 & 253 & 30,35 \\
\hline
\end{tabular}

$a$ The positions of the second $\mathrm{O}$ vacancy in the most stable structures, i.e., $\mathrm{O}_{\mathrm{SL}}(1 \mathrm{~A}, 1 \mathrm{~B}), \mathrm{O}_{\mathrm{FS}}(1 \mathrm{~B}, 2 \mathrm{C})$, and $\mathrm{O}_{\mathrm{SS}}(2 \mathrm{C}, 2 \mathrm{D})$ (see Fig. 1 and Table 1 ), are denoted by lower-case letters, as shown in Fig. 2-4, and numbers. The numbers specify the positions of the removed $\mathrm{O}$ atom: 1 - in the first (surface) layer, 2 - in the second (subsurface) layer, and 3 - in the third (below a surface Ce or Y cation) layer. ${ }^{b}$ Relative energy with respect to the most stable structure, i.e., $\mathrm{O}_{\mathrm{FS}}(1 \mathrm{~B}, 2 \mathrm{C})-2 \mathrm{f} .{ }^{c}$ Formation energy of an $\mathrm{O}$ vacancy. ${ }^{d}$ Distance between two $\mathrm{O}$ vacancies. ${ }^{e}$ Positions of the $\mathrm{Ce}^{3+}$ cations (see numbers in Fig. S1).

can facilitate the removal of surface oxygen atoms in comparison with those on the undoped ceria surface. Thus, the difference between the formation energies of an oxygen vacancy on the surface and in the subsurface layer of the oxide is reduced to only $0.10 \mathrm{eV}$ from the notably larger value of $0.33 \mathrm{eV}$ for the bare ceria surface.

A comparison of the locations of vacancies in different structures suggests that two $O$ vacancies may be either close to or far from each other, but it is not favorable to remove an $\mathrm{O}$ atom located between two $\mathrm{Y}^{3+}$ cations.

In summary, doping by $\mathrm{Y}$ does not influence the formation energy of an $\mathrm{O}$ vacancy in the subsurface region. However, the formation energy of a surface vacancy is reduced in comparison with that for the undoped surface and becomes close to the formation energy of a subsurface vacancy.

This finding agrees with the results of a recent experimental study of relationships between the structural features and activity in the water-gas shift (WGS) of gold catalysts supported on Y-doped ceria $\left(1.0,2.5, \quad 5.0\right.$ and $\left.7.5 \mathrm{wt} \% \mathrm{Y}_{2} \mathrm{O}_{3}\right){ }^{41}$ 
Temperature-programmed reduction measurements revealed that the doping of ceria with $\mathrm{Y}_{2} \mathrm{O}_{3}$ affected the reduction behavior. The effect was stronger when the doped ceria supports were prepared by impregnation rather than coprecipitation. The improved reducibility of the gold catalysts on ceria with predominant surface modification (impregnated samples) was closely correlated with better WGS performance in comparison with the gold samples on supports prepared by coprecipitation with prevailing bulk modification by Y. A nanoscale 3D electron microscopy study of La-doped ceria by Collins et al. also showed that reduction occurred predominantly at the surface of nanoparticles, as estimated from the locations of $\mathrm{Ce}^{3+}$ ions. ${ }^{9}$

3.1.3 Stoichiometric systems with four yttrium ions. We obtained structures with four $\mathrm{Y}^{3+}$ cations and two $\mathrm{O}$ vacancies by adding a pair of $\mathrm{Y}^{3+}$ cations to the most stable structures with two $\mathrm{Y}^{3+}$ cations and one $\mathrm{O}$ vacancy, i.e., $\mathrm{O}_{\mathrm{FS}}(1 \mathrm{~B}, 2 \mathrm{C})$ and $\mathrm{O}_{\mathrm{SS}}(2 \mathrm{C}, 2 \mathrm{D})$, and creating a new $\mathrm{O}$ vacancy. These added $\mathrm{Y}^{3+}$ cations and the new $\mathrm{O}$ vacancy were positioned according to the finding (see above) that pairs of $\mathrm{Y}^{3+}$ cations tend to stay close to each other near an oxygen vacancy. We identified five lowestenergy structures of this kind with stabilities within a range of $0.10 \mathrm{eV}$ (Table 3 ). Some of these structures have a combination of $\mathrm{Y}$ ions in the surface and subsurface layers, whereas in the other structures both Y pairs are in the subsurface layer and the $\mathrm{O}$ vacancies are in the subsurface or second subsurface layer. In $\mathrm{O}_{\mathrm{FS}}(1 \mathrm{~B}, 2 \mathrm{C}) / \mathrm{O}_{\mathrm{FS}}(1 \mathrm{H}, 2 \mathrm{~F})$ and $\mathrm{O}_{\mathrm{SS}}(2 \mathrm{C}, 2 \mathrm{D}) / \mathrm{O}_{\mathrm{SS}}(2 \mathrm{E}, 2 \mathrm{~F})$ the $\mathrm{Y}$ pairs are far apart, whereas in the other three structures (given in Table 3 in italics) the pairs are close to each other. In summary, one can see from Table 3 that structures that contain $\mathrm{O}$ vacancies on the surface are less stable than those with vacancies in the first and second subsurface layers. It can also be seen that the combinations of two stable configurations of a $\mathrm{Y}^{3+}$ pair and an $\mathrm{O}$ vacancy lead to stable structures with four $\mathrm{Y}^{3+}$ cations and two $\mathrm{O}$ vacancies.

Table 3 Energetic (in eV) and structural (in pm) characteristics of $\mathrm{CeO}_{2}(111)$ structures containing four $\mathrm{Y}^{3+}$ cations and two $\mathrm{O}$ vacancies

\begin{tabular}{lccr}
\hline Structure $^{a}$ & $E_{\text {rel }}{ }^{b}$ & $\mathrm{Y}^{2} \mathrm{Y}^{c}$ & $\Delta \mathrm{Y}^{c} \mathrm{Y}^{d}$ \\
\hline$O_{F S}(1 B, 2 C) / O_{S L}(1 A, 1 N)$ & 0.64 & $414 ; 421$ & 4 \\
$O_{F S}(1 B, 2 C) / O_{F S}(1 A, 1 N)$ & 0.19 & $407 ; 399$ & -3 \\
$O_{F S}(1 B, 2 C) / O_{S S}(2 D, 2 Q)$ & 0.51 & $461 ; 402$ & 51 \\
$O_{F S}(1 B, 2 C) / O_{S L}(1 A, 1 L)$ & 0.80 & $408 ; 455$ & -2 \\
$\mathrm{O}_{\mathrm{FS}}(1 \mathrm{~B}, 2 \mathrm{C}) / \mathrm{O}_{\mathrm{FS}}(1 \mathrm{H}, 2 \mathrm{~F})$ & 0.00 & $408 ; 410$ & -2 \\
$O_{F S}(1 B, 2 C) / O_{F S}(1 R, 2 M)$ & 0.10 & $408 ; 409$ & -2 \\
$\mathrm{O}_{\mathrm{FS}}(1 \mathrm{~B}, 2 \mathrm{C}) / \mathrm{O}_{\mathrm{FS}}(1 \mathrm{~S}, 2 \mathrm{~T})$ & 0.14 & $410 ; 408$ & 0 \\
$O_{S S}(2 C, 2 D) / O_{S S}(1 N, 1 B)$ & 0.64 & $404 ; 417$ & -2 \\
$O_{S S}(2 C, 2 D) / O_{S S}(1 L, 2 K)$ & 0.37 & $396 ; 421$ & -10 \\
$O_{S S}(2 C, 2 D) / O_{S S}(2 K, 2 M)$ & 0.05 & $396 ; 407$ & -10 \\
$\mathrm{O}_{S S}(2 \mathrm{C}, 2 \mathrm{D}) / \mathrm{O}_{\mathrm{SS}}(2 \mathrm{E}, 2 \mathrm{~F})$ & 0.01 & $405 ; 406$ & -1 \\
$O_{S S}(2 C, 2 D) / O_{S S}(2 M, 2 Q)$ & 0.10 & $408 ; 399$ & 2
\end{tabular}

${ }^{a}$ Positions of $\mathrm{Y}^{3+}$ cations as shown in Fig. 1. Structure names in italics indicate that both $\mathrm{Y}^{3+}$ pairs are located close to each other. ${ }^{b}$ Relative energy with respect to the most stable structure, i.e., $\mathrm{O}_{\mathrm{FS}}(1 \mathrm{~B}, 2 \mathrm{C}) /$ $\mathrm{O}_{\mathrm{FS}}(1 \mathrm{H}, 2 \mathrm{~F}){ }^{c}$ Distances between two nearest $\mathrm{Y}$ cations. ${ }^{d}$ Difference between the $\mathrm{Y}-\mathrm{Y}$ distances in the structure with four $\mathrm{Y}^{3+}$ cations and the structures with two $\mathrm{Y}^{3+}$ cations, i.e., $\mathrm{O}_{\mathrm{FS}}(1 \mathrm{~B}, 2 \mathrm{C})(410 \mathrm{pm})$ and $\mathrm{O}_{\mathrm{SS}}(2 \mathrm{C}, 2 \mathrm{D})(406 \mathrm{pm})$, respectively.

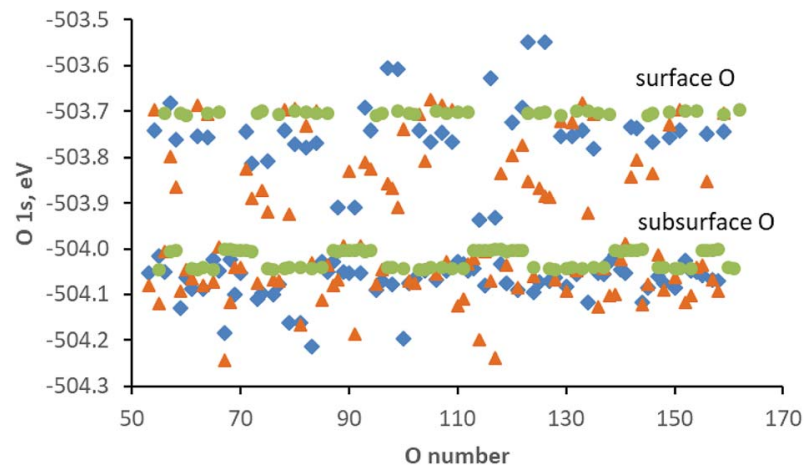

Fig. 4 Estimated $\mathrm{O}$ 1s core-level energies for the pristine $\mathrm{CeO}_{2}(111)$ structure (green bullets) and the two structures with two yttrium ions, i.e., $\mathrm{O}_{\mathrm{SL}}(1 \mathrm{~A}, 1 \mathrm{~B})$ (blue rhombuses) and $\mathrm{O}_{\mathrm{SL}}(2 \mathrm{C}, 2 \mathrm{D})$ (orange triangles).

3.1.4 Influence of yttrium on the basicity of surface oxygen centers. We used the most stable Y-doped structures to estimate changes in the basicity of the surface oxygen centers. According to earlier studies, a shift in the O 1s core level is correlated with the basicity of the oxygen centers, as estimated from the proton affinity of these centers - a less stable $O$ 1s core level (with a lower absolute energy $E(\mathrm{O} 1 \mathrm{~s})$ ) corresponds to a more basic oxygen center. ${ }^{42}$ It was estimated that a destabilization of the $\mathrm{O}$ 1s core level by $1.0 \mathrm{eV}$ corresponds to an increase in the proton affinity of the $\mathrm{O}$ center of $c a .80 \mathrm{~kJ} \mathrm{~mol}^{-1}$.

Oxygen atoms in pristine $\mathrm{CeO}_{2}(111)$ feature a very distinct separation of the $\mathrm{O} 1 \mathrm{~s}$ core levels - the surface and subsurface oxygen centers have $E(O$ 1s) values of around -503.7 and $-504.0 \mathrm{eV}$, respectively (see the green bullets in Fig. 4). The presence of yttrium cations and an oxygen vacancy modifies the $\mathrm{O}$ 1s energy values (see the brown triangles and blue rhombuses in Fig. 4 and S3A in ESI $\dagger$ ), and the $E(\mathrm{O} 1 \mathrm{~s})$ values extend over a somewhat wider interval from -503.5 to $-504.2 \mathrm{eV}$. For most of the oxygen centers, the $\mathrm{O} 1 \mathrm{~s}$ core level is stabilized by only up to $0.1 \mathrm{eV}$ (Fig. S3A in ESI $\dagger$ ). Oxygen centers close to yttrium ions and oxygen vacancies exhibit a more specific behavior. In the structure with both yttrium cations and the oxygen vacancy in the surface layer, the $\mathrm{O} 1 \mathrm{~s}$ level of the oxygen centers between two cations (in the first subsurface layer) is destabilized by $0.4 \mathrm{eV}$, and the other oxygen centers around each of the dopant cations that do not neighbor an oxygen vacancy are destabilized by $0.2 \mathrm{eV}$. The most basic oxygen centers in the structure are shown in indigo in Fig. S3B in ESI; $\uparrow$ they have $E(\mathrm{O} 1 \mathrm{~s})$ values that are lower in magnitude by $0.2-0.4 \mathrm{eV}$ than those of the surface oxygen centers in pristine ceria and are thus somewhat more basic. On the other hand, the $\mathrm{O} 1 \mathrm{~s}$ core levels of the oxygen centers around oxygen vacancies (shown in orange in Fig. S3B $\dagger$ ) are stabilized by $0.2 \mathrm{eV}$ with respect to the corresponding centers in the pristine ceria surface.

\subsection{Yttrium-doped $\mathrm{Ce}_{21} \mathrm{O}_{42}$ nanoparticles}

As well as the $\mathrm{CeO}_{2}(111)$ surface slab model, we modeled structures with two and four $\mathrm{Y}^{3+}$ cations by replacing two and four $\mathrm{Ce}^{4+}$ cations, respectively, using a smaller $\mathrm{Ce}_{21} \mathrm{O}_{42}$ 
nanoparticle (Fig. 5), from which one $\mathrm{O}$ atom was removed to maintain charge balance for each pair of $\mathrm{Y}^{3+}$ cations.

There are two- and three-coordinated $\mathrm{O}$ centers on the nanoparticle surface, whereas the subsurface $O$ centers are fourcoordinated. The two-coordinated oxygen ions $1 \mathrm{a}, 1 \mathrm{~b}, 1 \mathrm{c}$ and $1 \mathrm{~d}$ shown in Fig. 5 form a small (100) facet. The corresponding $\mathrm{Ce}^{4+}$ cations, which form part of this facet, are denoted as $1 \mathrm{~A}, 1 \mathrm{~B}, 1 \mathrm{C}$ and $1 \mathrm{D}$. The other two-coordinated $\mathrm{O}$ centers $(1 \mathrm{i}, 1 \mathrm{j}, 1 \mathrm{~m}, 1 \mathrm{n}$, and 10) are located at the corners of the nanoparticle. The threecoordinated $\mathrm{O}$ centers are denoted as $1 \mathrm{e}, 1 \mathrm{f}$, and $1 \mathrm{l}$, whereas the subsurface centers (four-coordinated) are denoted as $2 \mathrm{~g}, 2 \mathrm{~h}$ and $2 \mathrm{k}$. Owing to the small size of the nanoparticle, there is only one subsurface $\mathrm{Ce}^{4+}$ cation, which is denoted as $2 \mathrm{I}$.

3.2.1 Stoichiometric $\mathrm{Ce}_{21} \mathrm{O}_{42}$ nanoparticles containing two yttrium ions. We considered 23 structures with two $\mathrm{Y}^{3+}$ cations, which can be classified according to the type of oxygen center removed from the nanoparticle. The stability of the modeled structures was determined from their relative energies as shown in Table 4. In the most stable structure, i.e., $\mathrm{O}_{4 \mathrm{c}}(2 \mathrm{I}, 1 \mathrm{H})-2 \mathrm{~h}$ (Fig. 6a), one of the $\mathrm{Y}^{3+}$ cations is in the only subsurface position, whereas another $\mathrm{Y}^{3+}$ cation is in the (111) surface facet and

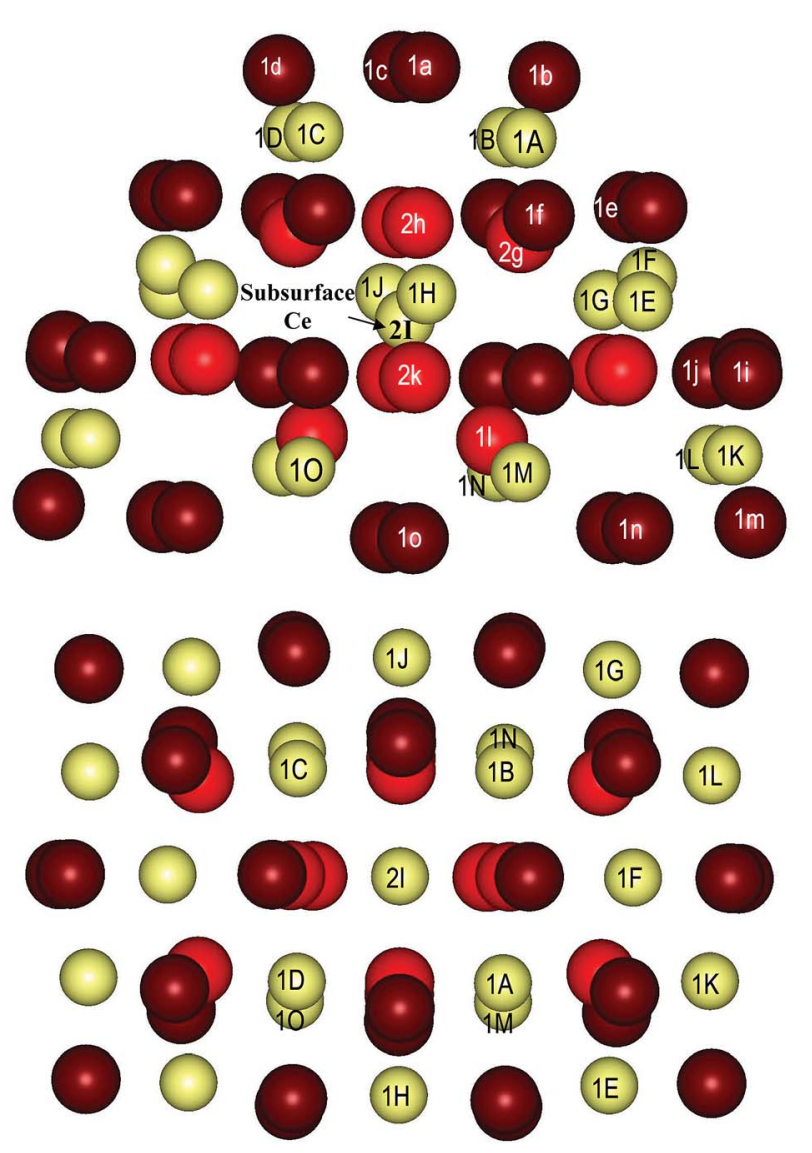

Fig. 5 Side and top views of $\mathrm{Ce}_{21} \mathrm{O}_{42}$ nanoparticle model. The positions of the cerium cations that are replaced by $\mathrm{Y}^{3+}$ are denoted by capital letters and numbers. The numbers indicate the position of the Ce cations in the surface or subsurface regions (only one Ce cation is in a subsurface position). The created $O$ vacancy is denoted by a lower-case letter, and the number indicates whether the oxygen center is in a surface (1) or subsurface (2) position. Color coding: $\mathrm{Ce}-$ yellow, surface $O$ centers - dark red, subsurface $O$ centers - red. the vacancy is created by removing one of the two fourcoordinated oxygen centers located between the $\mathrm{Y}^{3+}$ cations. In total, nine of the most stable structures have energies within a range of $0.20 \mathrm{eV}$. In these stable structures, both $\mathrm{Y}^{3+}$ cations replace $\mathrm{Ce}^{4+}$ cations from the top two layers, namely, the (100) facet and the layer below it, i.e., from the positions denoted as $\mathrm{A}-\mathrm{J}$; in six of the most stable structures the subsurface cation position $2 \mathrm{I}$ is occupied by $\mathrm{Y}^{3+}$. The $\mathrm{O}$ vacancy in these nine structures is formed by the removal of either a two-coordinated or a four-coordinated oxygen center.

The calculated energies of the other 14 modeled structures are higher by $0.36-1.21 \mathrm{eV}$ with respect to the most stable structure, i.e., $\mathrm{O}_{4 \mathrm{c}}(2 \mathrm{I}, 1 \mathrm{H})-2 \mathrm{~h}$. In these cases, yttrium dopants are present in all three possible cation layers of the smaller nanoparticle. In the least stable structures, of which the relative energies exceed $0.80 \mathrm{eV}$, both $\mathrm{Y}^{3+}$ cations are in surface positions (see the green bullets in Fig. 2B).

In general, the energetic stability of the doped structures under consideration is not related to the coordination number of the removed $\mathrm{O}$ center. The mutual location of two $\mathrm{Y}^{3+}$ cations does not determine the stability either. Hence, there is no clear correlation between the stability of a given structure and the corresponding $\mathrm{Y}-\mathrm{Y}$ distance (see the green bullets in Fig. 2A).

Table 4 Energetic (in eV), structural (in pm) and coordination characteristics of structures of the smaller ceria nanoparticle $\mathrm{Ce}_{21} \mathrm{O}_{42}$ containing two $\mathrm{Y}^{3+}$ cations and one $\mathrm{O}$ vacancy

\begin{tabular}{|c|c|c|c|c|c|}
\hline Structure $^{a}$ & $E_{\mathrm{rel}}^{b}$ & $\mathrm{Y}-\mathrm{Y}^{c}$ & $\mathrm{Y}-\mathrm{O}_{\mathrm{vac}}{ }^{d}$ & $\mathrm{~N}^{e}$ & $\mathrm{M}^{f}$ \\
\hline$O_{2 c}(1 A, 1 B)-1 b$ & 0.31 & 412 & 215,214 & 5,5 & 1 \\
\hline$O_{2 c}(1 A, 1 E)-1 a$ & 0.39 & 345 & 215,540 & 5,5 & 2 \\
\hline$O_{2 c}(1 A, 1 H)-1 a$ & 0.16 & 359 & 215,404 & 5,6 & 2 \\
\hline$O_{2 c}(1 A, 1 C)-1 a$ & 0.15 & 402 & 215,215 & 5,5 & 1 \\
\hline$O_{2 c}(1 \mathrm{~A}, 1 \mathrm{C})-1 \mathrm{~m}$ & 1.59 & 339 & 771,1005 & 5,5 & 2 \\
\hline$O_{2 c}(1 D, 1 E)-1 d$ & 0.40 & 817 & 214,778 & 5,5 & 0 \\
\hline$O_{2 c}(1 D, 1 E)-1 o$ & 1.07 & 800 & 817,553 & 6,5 & 0 \\
\hline$O_{2 c}(1 E, 1 F)-1 b$ & 0.39 & 358 & 533,373 & 5,6 & 2 \\
\hline$O_{2 c}(1 E, 1 F)-1 i$ & 1.01 & 357 & 211,411 & 4,6 & 2 \\
\hline$O_{2 c}(1 E, 1 H)-1 a$ & 0.37 & 362 & 540,404 & 5,6 & 1 \\
\hline$O_{2 c}(1 \mathrm{~K}, 1 \mathrm{~L})-1 \mathrm{~m}$ & 0.36 & 398 & 215,215 & 4,4 & 1 \\
\hline$O_{2 c}(1 K, 1 E)-1 i$ & 1.21 & 436 & 223,211 & 4,4 & 1 \\
\hline$O_{2 c}(1 K, 1 M)-1 n$ & 0.82 & 419 & 211,216 & 4,5 & 1 \\
\hline $\mathrm{O}_{2 \mathrm{c}}(1 \mathrm{~J}, 1 \mathrm{H})-1 \mathrm{a}$ & 0.13 & 740 & 714,404 & 6,6 & 0 \\
\hline $\mathrm{O}_{2 c}(2 \mathrm{I}, 1 \mathrm{~A})-1 a$ & 0.03 & 397 & 477,215 & 7,5 & 1 \\
\hline$O_{2 c}(2 I, 1 F)-1 b$ & 0.08 & 420 & 465,373 & 7,6 & 0 \\
\hline $\mathrm{O}_{2 c}(2 \mathrm{I}, 1 \mathrm{H})-1 \mathrm{a}$ & 0.04 & 381 & 477,404 & 7,6 & 1 \\
\hline$O_{2 c}(2 I, 1 M)-1 a$ & 0.44 & 361 & 477,690 & 7,6 & 1 \\
\hline$O_{2 c}(2 I, 1 M)-1 o$ & 0.62 & 360 & 440,215 & 8,5 & 2 \\
\hline$O_{3 c}(1 A, 1 E)-1 f$ & 1.24 & 392 & 239,228 & 5,4 & 1 \\
\hline$O_{3 c}(1 \mathrm{~A}, 1 \mathrm{H})-1 f$ & 1.01 & 394 & 239,228 & 5,5 & 1 \\
\hline$O_{3 c}(1 M, 1 N)-1 l$ & 0.55 & 555 & 223,223 & 5,5 & 0 \\
\hline$O_{4 c}(2 I, 1 H)-2 h$ & 0.00 & 399 & 244,228 & 7,5 & 1 \\
\hline$O_{4 c}(2 I, 1 A)-2 h$ & 0.19 & 410 & 244,230 & 7,5 & 1 \\
\hline $\mathrm{O}_{4 \mathrm{c}}(1 \mathrm{D}, 1 \mathrm{E})-2 \mathrm{~h}$ & 0.52 & 793 & 421,433 & 6,5 & 0 \\
\hline$O_{4 c}(2 I, 1 F)-2 g$ & 0.08 & 420 & 236,221 & 7,6 & 0 \\
\hline
\end{tabular}

${ }^{a}$ Position of $\mathrm{Y}^{3+}$ cations as shown in Fig. 5. Structure names in italics indicate that the $\mathrm{Y}^{3+}$ cations are located in nearest-neighboring positions. ${ }^{b}$ Relative energy with respect to the most stable structure, i.e., $\mathrm{O}_{4 \mathrm{c}}(2 \mathrm{I}, 1 \mathrm{H})-2 \mathrm{~h} .{ }^{c}$ Distance between two nearest $\mathrm{Y}$ cations. $d$ Distances between $\mathrm{Y}$ atoms and the $\mathrm{O}$ vacancy. ${ }^{e}$ Coordination numbers of $\mathrm{Y}^{3+}$ with respect to $\mathrm{O}$ atoms. ${ }^{f}$ Number of $\mathrm{O}$ atoms bound simultaneously to both $\mathrm{Y}^{3+}$ cations. 
a)
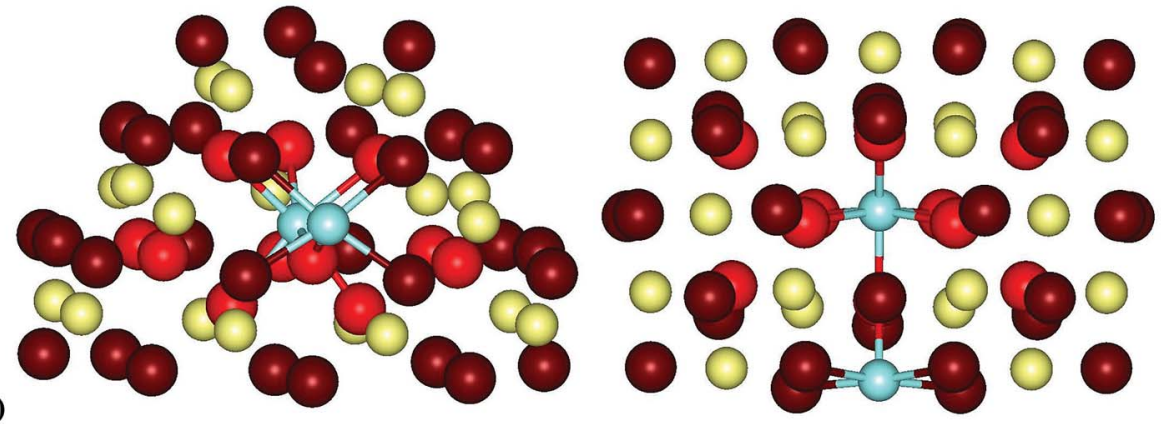

b)
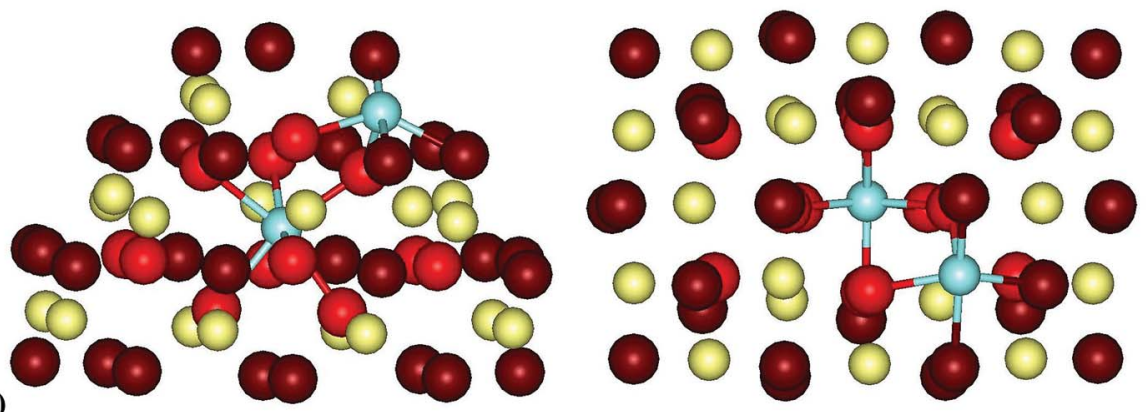

c)
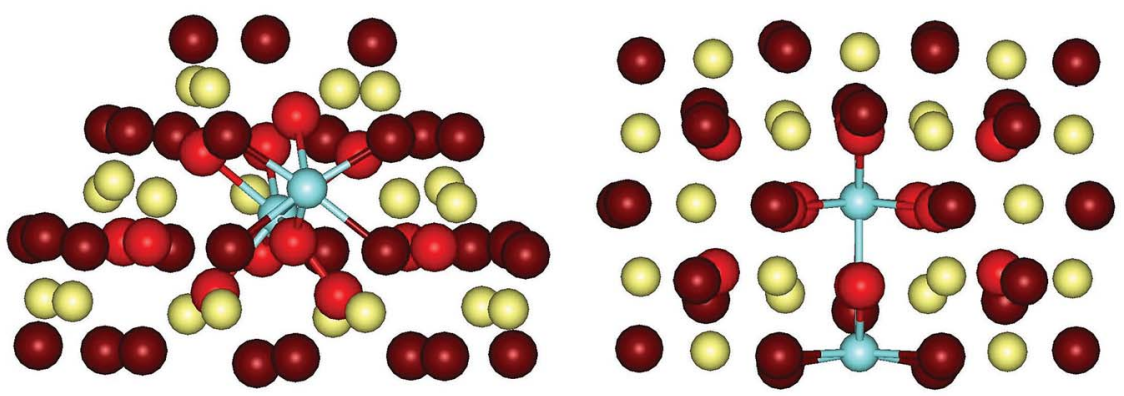

Fig. 6 Side (left column) and top (right column) views of optimized models of the most stable structures of the $\mathrm{Ce}_{21} \mathrm{O}_{42}$ nanoparticle with two $\mathrm{Y}^{3+}$ cations and one $\mathrm{O}$ vacancy: (a) $\mathrm{O}_{4 c}(2 \mathrm{l}, 1 \mathrm{H})-2 \mathrm{~h}$; (b) $\mathrm{O}_{2 \mathrm{c}}(2 \mathrm{l}, 1 \mathrm{~A})-1 \mathrm{a}$; and (c) $\mathrm{O}_{2 \mathrm{c}}(2 \mathrm{l}, 1 \mathrm{H})-1 \mathrm{a}$. Color coding: Ce - yellow, surface $\mathrm{O}$ centers - dark red, subsurface $O$ centers - red, $Y$ - light blue. For clarity the $Y-O$ bonds are shown.

The distances between the oxygen center that is removed and the $\mathrm{Y}^{3+}$ cations are not crucial for the stability of a given $\mathrm{Ce}_{19} \mathrm{Y}_{2} \mathrm{O}_{41}$ structure (Table 4), which is partly due to the geometric flexibility of the nanoparticle model. For instance, in structures that are almost the most stable, namely, $\mathrm{O}_{2 \mathrm{c}}(2 \mathrm{I}, 1 \mathrm{~A})-1 \mathrm{a}$ and $\mathrm{O}_{2 \mathrm{c}}(2 \mathrm{I}, 1 \mathrm{H})-1 \mathrm{a}$, the oxygen vacancy neighbors none or only one of the $\mathrm{Y}^{3+}$ cations, whereas in the $\mathrm{O}_{2 c}(1 \mathrm{~A}, 1 \mathrm{~B})-1 \mathrm{~b}$, $\mathrm{O}_{2 \mathrm{c}}(1 \mathrm{~K}, 1 \mathrm{M})-1 \mathrm{n}$, and $\mathrm{O}_{2 \mathrm{c}}(1 \mathrm{~K}, 1 \mathrm{E})-1 \mathrm{i}$ structures, which are destabilized in comparison with the most stable structure, i.e., $\mathrm{O}_{4 \mathrm{c}}(2 \mathrm{I}, 1 \mathrm{H})-2 \mathrm{~h}$, by $0.31,0.82$ and $1.21 \mathrm{eV}$, respectively, the oxygen vacancy neighbors both $\mathrm{Y}^{3+}$ ions.

3.2.2 Oxygen vacancy in nanoparticles containing two yttrium ions. From the most stable structures with two $\mathrm{Y}^{3+}$ cations, i.e., $\mathrm{O}_{4 \mathrm{c}}(2 \mathrm{I}, 1 \mathrm{H})-2 \mathrm{~h}$ and $\mathrm{O}_{2 \mathrm{c}}(2 \mathrm{I}, 1 \mathrm{~A})-1 \mathrm{a}$, we made models with a second $\mathrm{O}$ vacancy by removing one of the twocoordinated $\mathrm{O}$ centers (Table 5). Six models derived from $\mathrm{O}_{4 \mathrm{c}}(2 \mathrm{I}, 1 \mathrm{H})-2 \mathrm{~h}$ were considered: in four of them an $\mathrm{O}$ center was removed from the (100) facet, whereas in the remaining models an $\mathrm{O}$ center was removed from an edge site. The coordination number and location of the second removed $\mathrm{O}$ center are specified at the beginning and end, respectively, of the structure notation. For instance, the notation $\mathrm{O}_{2 c}\left(\mathrm{O}_{2 c}(2 \mathrm{I}, 1 \mathrm{~A})-1 \mathrm{a}\right)-1 \mathrm{~b}$ means that an $\mathrm{O}$ vacancy was created in the two-coordinated $1 \mathrm{~b}$ position of the $\mathrm{O}_{2 \mathrm{c}}(2 \mathrm{I}, 1 \mathrm{~A})-1 \mathrm{a}$ structure. The removal of an $\mathrm{O}$ center generates two $\mathrm{Ce}^{3+}$ cations. In all structures, both $\mathrm{Ce}^{4+}$ cations that were reduced were positioned directly adjacent to the site of the removed $\mathrm{O}$ center, except for the $\mathrm{O}_{2 c}\left(\mathrm{O}_{2 \mathrm{c}}(2 \mathrm{I}, 1 \mathrm{~A})\right.$ $1 \mathrm{a})-1 \mathrm{~b}$ structure, in which the second removed $\mathrm{O}$ atom was initially bound to surface $\mathrm{Y}^{3+}$ cations.

The most stable structure is $\mathrm{O}_{2 \mathrm{c}}\left(\mathrm{O}_{2 \mathrm{c}}(2 \mathrm{I}, 1 \mathrm{~A})-1 \mathrm{a}\right)-1 \mathrm{c}$, in which the two vacancies are located opposite each other in the (100) facet with $E_{\mathrm{vac}}=1.87 \mathrm{eV}$. The latter value is slightly lower than $2.04 \mathrm{eV}$, which we calculated for the pristine $\mathrm{Ce}_{21} \mathrm{O}_{42}$ nanoparticle with the same locations of the $\mathrm{O}$ vacancy and $\mathrm{Ce}^{3+}$ cations. Note, however, that the lowest formation energy of an $\mathrm{O}$ vacancy in the $\mathrm{Ce}_{21} \mathrm{O}_{42}$ nanoparticle determined with the same computational setup, namely, $1.67 \mathrm{eV},{ }^{28,29}$ indicates that the presence of $\mathrm{Y}^{3+}$ does not facilitate the formation of an $\mathrm{O}$ vacancy. The formation energies of an $\mathrm{O}$ vacancy in the other positions in the (100) facet of the pristine $\mathrm{Ce}_{21} \mathrm{O}_{42}$ nanoparticle are similar, namely, $2.07 \mathrm{eV}(1 \mathrm{a}), 2.07 \mathrm{eV}$ (1b) and $2.20 \mathrm{eV}$ (1d). For the removal of an $\mathrm{O}$ center from the $1 \mathrm{~b}, 1 \mathrm{~d}$ and $1 \mathrm{i}$ positions 
Table 5 Energetic (in eV) and structural (in pm) characteristics of the modeled structures of the smaller ceria nanoparticle $\mathrm{Ce}_{21} \mathrm{O}_{42}$ containing two $\mathrm{Y}^{3+}$ cations and two $\mathrm{O}$ vacancies

\begin{tabular}{lccll}
\hline Structure $^{a}$ & $E_{\text {rel }}{ }^{b}$ & $E_{\text {vac }}{ }^{c}$ & $\mathrm{O}_{\text {vac }}-\mathrm{O}_{\text {vac }}{ }^{d}$ & $\#$ Ce $^{e}$ \\
\hline $\mathrm{O}_{2 \mathrm{c}}\left(\mathrm{O}_{2 \mathrm{c}}(2 \mathrm{I}, 1 \mathrm{~A})-1 \mathrm{a}\right)-1 \mathrm{c}$ & 0.00 & 1.87 & 459 & 1,4 \\
$\mathrm{O}_{2 \mathrm{c}}\left(\mathrm{O}_{2 \mathrm{c}}(2 \mathrm{I}, 1 \mathrm{~A})-1 \mathrm{a}\right)-1 \mathrm{~b}$ & 0.46 & 2.33 & 319 & 1,19 \\
$\mathrm{O}_{2 \mathrm{c}}\left(\mathrm{O}_{2 \mathrm{c}}(2 \mathrm{I}, 1 \mathrm{~A})-1 \mathrm{a}\right)-1 \mathrm{~d}$ & 0.42 & 2.29 & 319 & 4,13 \\
$\mathrm{O}_{2 \mathrm{c}}\left(\mathrm{O}_{2 \mathrm{c}}(2 \mathrm{I}, 1 \mathrm{~A})-1 \mathrm{a}\right)-1 \mathrm{i}$ & 0.21 & 2.08 & 742 & 2,10 \\
$\mathrm{O}_{2 \mathrm{c}}\left(\mathrm{O}_{4 \mathrm{c}}(2 \mathrm{I}, 1 \mathrm{H})-2 \mathrm{~h}\right)-1 \mathrm{a}$ & 0.97 & 2.85 & 262 & 13,18 \\
$\mathrm{O}_{2 \mathrm{c}}\left(\mathrm{O}_{4 \mathrm{c}}(2 \mathrm{I}, 1 \mathrm{H})-2 \mathrm{~h}\right)-1 \mathrm{~b}$ & 0.38 & 2.25 & 379 & 1,18 \\
$\mathrm{O}_{2 \mathrm{c}}\left(\mathrm{O}_{4 \mathrm{c}}(2 \mathrm{I}, 1 \mathrm{H})-2 \mathrm{~h}\right)-1 \mathrm{c}$ & 0.16 & 2.03 & 486 & 1,4 \\
$\mathrm{O}_{2 \mathrm{c}}\left(\mathrm{O}_{4 \mathrm{c}}(2 \mathrm{I}, 1 \mathrm{H})-2 \mathrm{~h}\right)-1 \mathrm{~d}$ & 0.30 & 2.18 & 379 & 4,13 \\
$\mathrm{O}_{2 \mathrm{c}}\left(\mathrm{O}_{4 \mathrm{c}}(2 \mathrm{I}, 1 \mathrm{H})-2 \mathrm{~h}\right)-1 \mathrm{o}$ & 0.85 & 2.72 & 527 & 7,11 \\
$\mathrm{O}_{2 \mathrm{c}}\left(\mathrm{O}_{4 \mathrm{c}}(2 \mathrm{I}, 1 \mathrm{H})-2 \mathrm{~h}\right)-1 \mathrm{i}$ & 0.14 & 2.01 & 613 & 2,10
\end{tabular}

${ }^{a}$ The letters indicate the positions of the $\mathrm{Y}^{3+}$ cations and removed $\mathrm{O}$ centers shown in Fig. 5, whereas the numbers indicate whether the $\mathrm{Y}^{3+}$ cation or removed $\mathrm{O}$ center is located in the first (surface) layer, 1, or the second (subsurface) layer, 2. In parentheses is the structure with two $\mathrm{Y}^{3+}$ cations and one $\mathrm{O}_{\text {vac }}$ from which the $\mathrm{O}$ center is removed. ${ }^{b}$ Relative energy with respect to the most stable structure, i.e., $\mathrm{O}_{2 \mathrm{c}}\left(\mathrm{O}_{2 \mathrm{c}}(2 \mathrm{I}, 1 \mathrm{~A})-1 \mathrm{a}\right)-1 \mathrm{c}$. ${ }^{c}$ Formation energy of an $\mathrm{O}$ vacancy. $d$ Distance between two $\mathrm{O}$ vacancies. ${ }^{e}$ Positions of the $\mathrm{Ce}^{3+}$ cations (see numbers in Fig. S2).

of the $\mathrm{O}_{2 \mathrm{c}}(2 \mathrm{I}, 1 \mathrm{~A})-1 \mathrm{a}$ structure, the $E_{\mathrm{vac}}$ values are at least $0.2 \mathrm{eV}$ higher than the value for $\mathrm{O}_{2 c}\left(\mathrm{O}_{2 c}(2 \mathrm{I}, 1 \mathrm{~A})-1 \mathrm{a}\right)-1 \mathrm{c}$.

For the removal of an $\mathrm{O}$ center from the $\mathrm{O}_{2 \mathrm{c}}(2 \mathrm{I}, 1 \mathrm{H})-2 \mathrm{~h}$ structure, the $E_{\mathrm{vac}}$ values vary from $2.01 \mathrm{eV}$ to $2.85 \mathrm{eV}$. In a similar way to the removal of an $\mathrm{O}$ center from $\mathrm{O}_{2 \mathrm{c}}(2 \mathrm{I}, 1 \mathrm{~A})-1 \mathrm{a}$, the lowest $E_{\text {vac }}$ values were also calculated for the removal of an $\mathrm{O}$ center from the $1 \mathrm{i}$ and $1 \mathrm{c}$ positions and are 2.01 and $2.03 \mathrm{eV}$, respectively. Notably, we were unable to find any correlation between the distances between two $\mathrm{O}$ vacancies $\left(\mathrm{O}_{\mathrm{vac}}-\mathrm{O}_{\mathrm{vac}}\right.$ in Table 5) and the $E_{\mathrm{vac}}$ values.

3.2.3 Stoichiometric $\mathrm{Ce}_{21} \mathrm{O}_{42}$ nanoparticles containing four yttrium ions. We also modeled nanoparticle structures with four $\mathrm{Y}^{3+}$ cations and two $\mathrm{O}$ vacancies. For this purpose, we used the two most stable structures with two $\mathrm{Y}^{3+}$ cations and one $\mathrm{O}$ vacancy, i.e., $\mathrm{O}_{4 \mathrm{c}}(2 \mathrm{I}, 1 \mathrm{H})-2 \mathrm{~h}$ and $\mathrm{O}_{2 \mathrm{c}}(2 \mathrm{I}, 1 \mathrm{~A})-1 \mathrm{a}$, together with the $\mathrm{O}_{2 \mathrm{c}}(1 \mathrm{~A}, 1 \mathrm{C})-1 \mathrm{a}$ structure, in which both $\mathrm{Y}^{3+}$ ions are located in the (100) facet (see Table 4). In each of these three structures we replaced two $\mathrm{Ce}^{4+}$ cations by $\mathrm{Y}^{3+}$ cations and concomitantly removed one $\mathrm{O}$ atom. The new $\mathrm{Y}^{3+}$ sites and $\mathrm{O}$ vacancy are accordingly reflected in the notation of the structures. For instance, the notation $\mathrm{O}_{2 \mathrm{c}}(1 \mathrm{~L}, 1 \mathrm{~F})-1 \mathrm{~m} / \mathrm{O}_{4 \mathrm{c}}(2 \mathrm{I}, 1 \mathrm{H})-2 \mathrm{~h}$ means that in the $\mathrm{O}_{4 \mathrm{c}}(2 \mathrm{I}, 1 \mathrm{H})-2 \mathrm{~h}$ structure the two $\mathrm{Ce}^{4+}$ cations in the $1 \mathrm{~L}$ and $1 \mathrm{~F}$ positions are replaced by $\mathrm{Y}^{3+}$ cations and the second $\mathrm{O}$ vacancy is formed in the $1 \mathrm{~m}$ position. The calculated results for the $\mathrm{Ce}_{17} \mathrm{Y}_{4} \mathrm{O}_{40}$ structures are summarized in Table 6 .

There are six modeled structures with relative energies within a range of $0.23 \mathrm{eV}$, and in all of these one of the yttrium ions is located in the subsurface position denoted as 2I (see Fig. 7). The relative energy of the other studied structures ranges between 0.29 and $2.60 \mathrm{eV}$. Note that in several of these destabilized structures a $\mathrm{Y}^{3+}$ cation also occupies the subsurface $2 \mathrm{I}$ position, which hence does not seem to be a decisive factor for the stabilization of the $\mathrm{Ce}_{17} \mathrm{Y}_{4} \mathrm{O}_{40}$ structures.

The least stable structure is $\mathrm{O}_{4 \mathrm{c}}(1 \mathrm{M}, 1 \mathrm{O})-2 \mathrm{k} / \mathrm{O}_{4 \mathrm{c}}(2 \mathrm{I}, 1 \mathrm{H})-2 \mathrm{~h}$, in which the four-coordinated $\mathrm{O}$ center between the $\mathrm{Y}^{3+}$ ions in the
Table 6 Energetic (in eV) and structural (in pm) characteristics of structures of the smaller ceria nanoparticle $\mathrm{Ce}_{21} \mathrm{O}_{42}$ containing four $\mathrm{Y}^{3+}$ cations and two $\mathrm{O}$ vacancies $\left(\mathrm{Ce}_{17} \mathrm{Y}_{4} \mathrm{O}_{40}\right)$

\begin{tabular}{|c|c|c|c|}
\hline Structure $^{a}$ & $E_{\text {rel }}^{b}$ & $\mathrm{Y}-\mathrm{Y}^{c}$ & $\Delta \mathrm{Y}-\mathrm{Y}^{d}$ \\
\hline$O_{2 c}(1 B, 1 A)-1 b / O_{4 c}(2 I, 1 H)-2 h$ & 0.40 & 397,408 & 9 \\
\hline$O_{2 c}(1 B, 1 D)-1 c / O_{4 c}(2 I, 1 H)-2 h$ & 0.19 & 400,395 & -4 \\
\hline$O_{2 c}(1 E, 1 F)-1 b / O_{4 c}(2 I, 1 H)-2 h$ & 0.66 & 356,407 & 8 \\
\hline $\mathrm{O}_{2 \mathrm{c}}(1 \mathrm{~K}, 1 \mathrm{~L})-1 \mathrm{~b} / \mathrm{O}_{4 \mathrm{c}}(2 \mathrm{I}, 1 \mathrm{H})-2 \mathrm{~h}$ & 1.88 & 338,408 & 9 \\
\hline $\mathrm{O}_{2 \mathrm{c}}(1 \mathrm{~K}, 1 \mathrm{~L})-1 \mathrm{~m} / \mathrm{O}_{4 \mathrm{c}}(2 \mathrm{I}, 1 \mathrm{H})-2 \mathrm{~h}$ & 0.23 & 400,400 & 1 \\
\hline$O_{2 c}(1 \mathrm{~K}, 1 \mathrm{~F})-1 \mathrm{~m} / \mathrm{O}_{4 c}(2 \mathrm{I}, 1 \mathrm{H})-2 \mathrm{~h}$ & 0.04 & 354,399 & 0 \\
\hline$O_{2 c}(1 L, 1 F)-1 m / O_{4 c}(2 I, 1 H)-2 h$ & 0.00 & 354,401 & 2 \\
\hline$O_{2 c}(1 L, 1 F)-1 j / O_{4 c}(2 I, 1 H)-2 h$ & 0.67 & 382,401 & 2 \\
\hline $\mathrm{O}_{2 \mathrm{c}}(1 \mathrm{~L}, 1 \mathrm{G})-1 \mathrm{j} / \mathrm{O}_{4 \mathrm{c}}(2 \mathrm{I}, 1 \mathrm{H})-2 \mathrm{~h}$ & 0.86 & 437,401 & 2 \\
\hline$O_{2 c}(1 M, 1 O)-1 o / O_{4 c}(2 I, 1 H)-2 h$ & 0.95 & 393,396 & -3 \\
\hline$O_{4 c}(1 M, 1 O)-2 k / O_{4 c}(2 I, 1 H)-2 h$ & 2.60 & 369,432 & 33 \\
\hline$O_{2 c}(1 B, 1 J)-1 b / O_{2 c}(2 I, 1 A)-1 a$ & 0.88 & 348,443 & 46 \\
\hline$O_{2 c}(1 B, 1 J)-1 c / O_{2 c}(2 I, 1 A)-1 a$ & 0.39 & 364,383 & -14 \\
\hline$O_{2 c}(1 G, 1 J)-1 b / O_{2 c}(2 I, 1 A)-1 a$ & 1.11 & 355,449 & 52 \\
\hline$O_{2 c}(1 G, 1 J)-1 c / O_{2 c}(2 I, 1 A)-1 a$ & 0.47 & 361,376 & -21 \\
\hline$O_{2 c}(1 \mathrm{~K}, 1 E)-1 i / O_{2 c}(2 I, 1 \mathrm{~A})-1 a$ & 1.01 & 439,398 & 1 \\
\hline $\mathrm{O}_{2 \mathrm{c}}(1 \mathrm{~K}, 1 \mathrm{~L})-1 \mathrm{~m} / \mathrm{O}_{2 \mathrm{c}}(2 \mathrm{I}, 1 \mathrm{~A})-1 \mathrm{a}$ & 0.18 & 404,398 & 1 \\
\hline $\mathrm{O}_{2 \mathrm{c}}(1 \mathrm{~L}, 1 \mathrm{G})-1 \mathrm{j} / \mathrm{O}_{2 \mathrm{c}}(2 \mathrm{I}, 1 \mathrm{~A})-1 \mathrm{a}$ & 0.92 & 440,398 & 1 \\
\hline$O_{2 c}(1 L, 1 F)-1 m / O_{2 c}(2 I, 1 A)-1 a$ & 0.04 & 352,393 & -4 \\
\hline$O_{2 c}(1 G, 1 F)-1 b / O_{2 d}(2 I, 1 A)-1 a$ & 1.06 & 356,417 & 20 \\
\hline$O_{3 c}(1 G, 1 F)-1 e / O_{2 c}(2 I, 1 A)-1 a$ & 1.26 & 397,390 & -7 \\
\hline$O_{2 c}(1 B, 1 D)-1 c / O_{2 c}(1 A, 1 C)-1 a$ & 0.38 & 403,403 & 1 \\
\hline $\mathrm{O}_{2 \mathrm{c}}(1 \mathrm{~K}, 1 \mathrm{~L})-1 \mathrm{~m} / \mathrm{O}_{2 \mathrm{c}}(1 \mathrm{~A}, 1 \mathrm{C})-1 \mathrm{a}$ & 0.29 & 402,403 & 1 \\
\hline $\mathrm{O}_{2 \mathrm{c}}(1 \mathrm{G}, 1 \mathrm{~L})-1 \mathrm{j} / \mathrm{O}_{2 \mathrm{c}}(1 \mathrm{~A}, 1 \mathrm{C})-1 \mathrm{a}$ & 1.09 & 442,410 & 8 \\
\hline $\mathrm{O}_{2 \mathrm{c}}(1 \mathrm{G}, 1 \mathrm{~J})-1 \mathrm{j} / \mathrm{O}_{2 \mathrm{c}}(1 \mathrm{~A}, 1 \mathrm{C})-1 \mathrm{a}$ & 0.88 & 346,410 & 8 \\
\hline
\end{tabular}

${ }^{a}$ The positions of $\mathrm{Y}^{3+}$ and $\mathrm{O}^{2-}$ ions are shown in Fig. 5. Structure names in italics indicate that both $\mathrm{Y}^{3+}$ pairs are located close to each other. $b$ Relative energy with respect to the most stable structure, i.e., $\mathrm{O}_{2 \mathrm{c}}(1 \mathrm{~L}, 1 \mathrm{~F})-1 \mathrm{~m} / \mathrm{O}_{4 \mathrm{c}}(2 \mathrm{I}, 1 \mathrm{H})-2 \mathrm{~h} .{ }^{c}$ Distances between two nearest $\mathrm{Y}$ cations. ${ }^{d}$ Difference between the $\mathrm{Y}-\mathrm{Y}$ distances in the structures with two $\mathrm{Y}^{3+}$ cations $\left(\mathrm{O}_{4 \mathrm{c}}(2 \mathrm{I}, 1 \mathrm{H})-2 \mathrm{~h}: 399 \mathrm{pm} ; \mathrm{O}_{2 \mathrm{c}}(2 \mathrm{I}, 1 \mathrm{~A})-1 \mathrm{a}\right.$ : $397 \mathrm{pm}$; and $\left.\mathrm{O}_{2 \mathrm{c}}(1 \mathrm{~A}, 1 \mathrm{C})-1 \mathrm{a}: 402 \mathrm{pm}\right)$ and the structure with four $\mathrm{Y}^{3+}$ cations.

$2 \mathrm{I}$ and $1 \mathrm{H}$ cation positions is removed. As a comparison, the $\mathrm{O}_{2 \mathrm{c}}(1 \mathrm{M}, 1 \mathrm{O})-1 \mathrm{o} / \mathrm{O}_{4 \mathrm{c}}(2 \mathrm{I}, 1 \mathrm{H})-2 \mathrm{~h}$ structure, which has the same four $\mathrm{Y}^{3+}$ positions but instead a two-coordinated $\mathrm{O}$ center (10) is removed, is more stable by $c a \cdot 1.7 \mathrm{eV}$ than $\mathrm{O}_{4 \mathrm{c}}(1 \mathrm{M}, 1 \mathrm{O})-2 \mathrm{k} /$ $\mathrm{O}_{4 \mathrm{c}}(2 \mathrm{I}, 1 \mathrm{H})-2 \mathrm{~h}$. In the latter, four $\mathrm{Y}^{3+}$ cations form a triangular pyramid, inside which the $2 \mathrm{k}$ center is located. The distance between a $\mathrm{Y}^{3+}$ cation in the pyramid base and the top $\mathrm{Y}^{3+}$ cation is greater by $35 \mathrm{pm}$ in comparison with that in $\mathrm{O}_{4 \mathrm{c}}(1 \mathrm{M}, 1 \mathrm{O})-1 \mathrm{O} /$ $\mathrm{O}_{4 \mathrm{c}}(2 \mathrm{I}, 1 \mathrm{H})-2 \mathrm{~h}$ as a consequence of the removal of the $2 \mathrm{k}$ center.

The $\mathrm{O}_{2 \mathrm{c}}(1 \mathrm{~B}, 1 \mathrm{D})-1 \mathrm{c} / \mathrm{O}_{2 \mathrm{c}}(1 \mathrm{~A}, 1 \mathrm{C})-1 \mathrm{a}$ structure, in which all four $\mathrm{Y}^{3+}$ cations are in the (100) facet and the two removed $\mathrm{O}$ centers were located opposite each other in the same facet, is less stable by $0.38 \mathrm{eV}$ than the most stable structure, namely, $\mathrm{O}_{2 \mathrm{c}}(1 \mathrm{~L}, 1 \mathrm{~F})-$ $1 \mathrm{~m} / \mathrm{O}_{4 \mathrm{c}}(2 \mathrm{I}, 1 \mathrm{H})-2 \mathrm{~h}$.

Table 6 also shows the differences between the $\mathrm{Y}-\mathrm{Y}$ distances in the parent structures (with two $\mathrm{Y}^{3+}$ cations and one $\mathrm{O}$ vacancy) and the corresponding resulting structures with four $\mathrm{Y}^{3+}$ cations and two $\mathrm{O}$ vacancies, denoted as $\Delta \mathrm{Y}-\mathrm{Y}$. In some structures (including three of the most stable structures) this distance is essentially identical or only changes by up to $8 \mathrm{pm}$. However, when all the modeled structures are considered no clear correlation between the stability and the variations in the Y-Y distance can be observed. 
a)
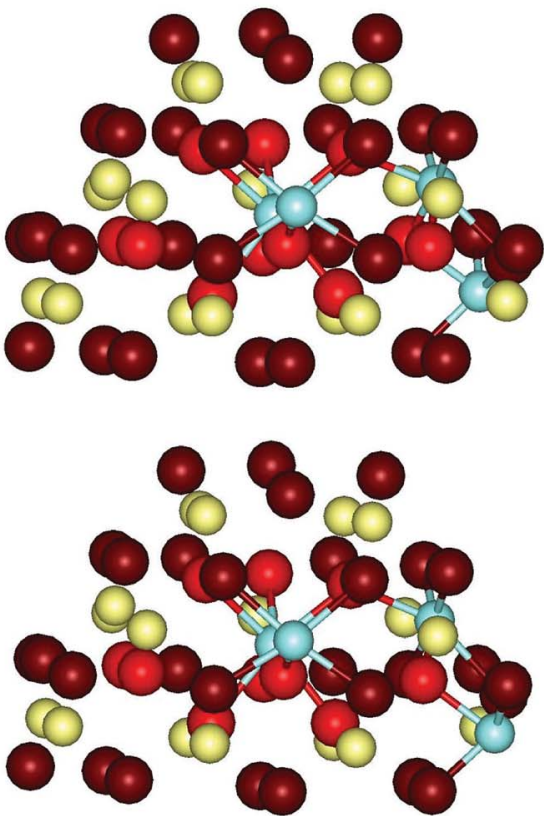

b)

c)

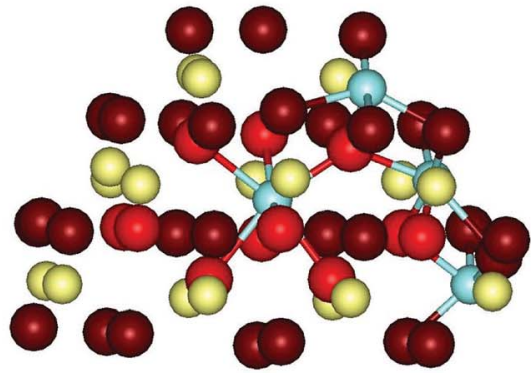

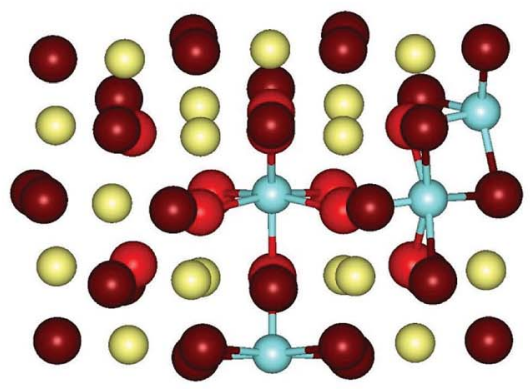
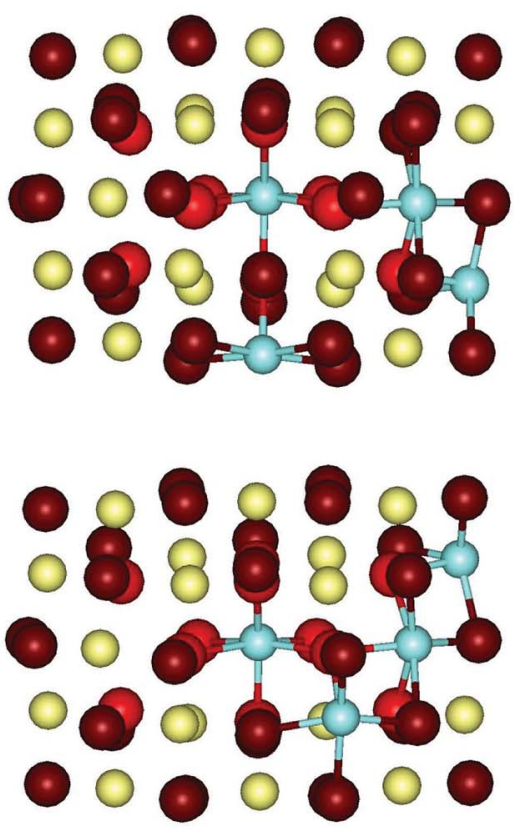

Fig. 7 Side (left column) and top (right column) views of optimized models of the most stable structures of the $\mathrm{Ce}_{21} \mathrm{O}_{42}$ nanoparticle with four $\mathrm{Y}^{3+}$ cations and two $\mathrm{O}$ vacancies: (a) $\mathrm{O}_{2 c}(1 \mathrm{~L}, 1 \mathrm{~F})-1 \mathrm{~m} / \mathrm{O}_{4 c}(2 \mathrm{l}, 1 \mathrm{H})-2 \mathrm{~h}$; (b) $\mathrm{O}_{2 c}(1 \mathrm{~K}, 1 \mathrm{~F})-1 \mathrm{~m} / \mathrm{O}_{4 c} \mathrm{c}(2 \mathrm{l}, 1 \mathrm{H})-2 \mathrm{~h}$; and $(\mathrm{c}) \mathrm{O}_{2 \mathrm{c}}(1 \mathrm{~L}, 1 \mathrm{~F})-1 \mathrm{~m} / \mathrm{O}_{2 c}(2 \mathrm{l}, 1 \mathrm{~A})-1 \mathrm{a}$. Color coding: $\mathrm{Ce}$ - yellow, surface $\mathrm{O}$ centers - dark red, subsurface $\mathrm{O}$ centers - red, $\mathrm{Y}$ - light blue. For clarity the $\mathrm{Y}-\mathrm{O}$ bonds are shown.

In summary, the stability of the Y-doped structures based on the $\mathrm{Ce}_{21} \mathrm{O}_{42}$ nanoparticle is not clearly determined by only one factor, such as the coordination of the removed $\mathrm{O}$ centers or the $\mathrm{Y}-\mathrm{Y}$ and $\mathrm{Y}-\mathrm{O}_{\text {vac }}$ distances. In general, it can be seen that the structures in which one of the $\mathrm{Y}^{3+}$ cations is located in a subsurface position are among the most stable structures.

\subsection{Yttrium-doped $\mathrm{Ce}_{40} \mathrm{O}_{80}$ larger nanoparticles}

3.3.1 Stoichiometric nanoparticles containing two yttrium ions. The results for 26 modeled structures based on the larger $\mathrm{Ce}_{40} \mathrm{O}_{80}$ nanoparticle with different combinations of two $\mathrm{Y}^{3+}$ cations and one $\mathrm{O}$ vacancy are shown in Table 7; see Fig. 8 for details of the positions of the $\mathrm{Y}^{3+}$ cations and $\mathrm{O}$ vacancies. The most stable structure is $\mathrm{O}_{2 \mathrm{c}}(1 \mathrm{E}, 1 \mathrm{~K})-1 \mathrm{a}$, which has symmetrically situated surface $\mathrm{Y}^{3+}$ ions at the apexes of the nanoparticle and an $\mathrm{O}$ center removed from a two-coordinated position in the (100) facet. In an earlier study, the $\mathrm{Ce}^{4+}$ cations in these apex positions were found to be reduced more easily in comparison with the other $\mathrm{Ce}^{4+}$ cations in a $\mathrm{Ce}_{40} \mathrm{O}_{80}$ nanoparticle. ${ }^{28,29}$ The next five structures that are higher in energy exhibit similar stability, with relative energies in the range of $0.27-0.32 \mathrm{eV}$. In these structures, the $\mathrm{Y}^{3+}$ cations are in different types of location: (i) in neighboring subsurface positions, e.g., $\mathrm{O}_{2 \mathrm{c}}(2 \mathrm{H}, 2 \mathrm{O})-$ 1a; (ii) in distant subsurface positions, e.g., $\mathrm{O}_{2 \mathrm{c}}(2 \mathrm{H}, 2 \mathrm{~S})-1 \mathrm{a}$; (iii) in neighboring surface positions, e.g., $\mathrm{O}_{2 \mathrm{c}}(1 \mathrm{~B}, 1 \mathrm{E})-1 \mathrm{a}$; (iv) in distant-corner surface positions, e.g., $\mathrm{O}_{2 \mathrm{c}}(1 \mathrm{~L}, 1 \mathrm{R})-1 \mathrm{a}$; and $(\mathrm{v})$ in neighboring surface and subsurface positions, e.g., $\mathrm{O}_{2 \mathrm{c}}(1 \mathrm{~F}, 2 \mathrm{H})$ 1a. In all these structures, the $\mathrm{O}$ vacancy is in the lowcoordinated surface position 1a. During geometry optimization of several structures with an $\mathrm{O}$ vacancy in the subsurface $2 \mathrm{e}$ position, the oxygen center from the 1 a position moved to the $2 \mathrm{e}$ vacancy site. Hence, the $\mathrm{O}_{2 \mathrm{e}}$ vacancy became an $\mathrm{O}_{1 \mathrm{a}}$ vacancy.

As a general trend, structures with $\mathrm{O}$ vacancies created by removing three-(1o and $1 \mathrm{f})$ or four-coordinated (2h and $2 \mathrm{l}$ ) centers are unstable, and such structures become stable only when the vacancy is created in the position of a two-coordinated $\mathrm{O}$ center (1a). For instance: (i) the $\mathrm{O}_{2 \mathrm{c}}(2 \mathrm{H}, 2 \mathrm{O})-1 \mathrm{a}$ structure is more stable by $0.51 \mathrm{eV}$ than $\mathrm{O}_{2 \mathrm{c}}(2 \mathrm{H}, 2 \mathrm{O})-2 \mathrm{~h}$; (ii) the $\mathrm{O}_{2 \mathrm{c}}(2 \mathrm{H}, 2 \mathrm{~S})$ 1a structure is more stable by $0.69 \mathrm{eV}$ than $\mathrm{O}_{2 \mathrm{c}}(2 \mathrm{H}, 2 \mathrm{~S})-2 \mathrm{~h}$; and (iii) the $\mathrm{O}_{2 \mathrm{c}}(1 \mathrm{~L}, 1 \mathrm{R})-1 \mathrm{a}$ structure is more stable by $1.43 \mathrm{eV}$ than $\mathrm{O}_{2 \mathrm{c}}(1 \mathrm{~L}, 1 \mathrm{R})-1 \mathrm{o}$. 
Table 7 Energetic (in eV), structural (in pm) and coordination characteristics of structures of the larger $\mathrm{Ce}_{40} \mathrm{O}_{80}$ ceria nanoparticle containing two $\mathrm{Y}^{3+}$ cations and one $\mathrm{O}$ vacancy

\begin{tabular}{|c|c|c|c|c|c|}
\hline Structure $^{a}$ & $E_{\text {rel }}^{b}$ & $\mathrm{Y}-\mathrm{Y}^{c}$ & $\mathrm{Y}-\mathrm{O}_{\mathrm{vac}}{ }^{d}$ & $\mathrm{~N}^{e}$ & $\mathbf{M}^{f}$ \\
\hline$O_{2 c}(1 A, 1 B)-1 a$ & 0.65 & 419 & $219 ; 214$ & 5,5 & 1 \\
\hline$O_{2 c}(1 A, 2 H)-1 a$ & 0.44 & 370 & $219 ; 446$ & 5,8 & 2 \\
\hline $\mathrm{O}_{2 \mathrm{c}}(1 \mathrm{~A}, 1 \mathrm{~L})-1 \mathrm{a}$ & 0.44 & 976 & $219 ; 900$ & 5,4 & 0 \\
\hline $\mathrm{O}_{2 \mathrm{c}}(1 \mathrm{~A}, 2 \mathrm{~S})-1 \mathrm{a}$ & 0.56 & 829 & $219 ; 945$ & 5,8 & 0 \\
\hline$O_{2 c}(1 A, 1 G)-1 a$ & 1.05 & 369 & $219 ; 567$ & 5,5 & 2 \\
\hline $\mathrm{O}_{2 \mathrm{c}}(1 \mathrm{E}, 1 \mathrm{~K})-1 \mathrm{a}$ & 0.00 & 1034 & $545 ; 789$ & 6,6 & 0 \\
\hline$O_{2 c}(1 B, 1 E)-1 a$ & 0.32 & 354 & $214 ; 545$ & 5,6 & 2 \\
\hline$O_{2 c}(1 F, 1 M)-1 g$ & 0.50 & 383 & $408 ; 214$ & 7,5 & 2 \\
\hline$O_{2 c}(1 F, 2 H)-1 a$ & 0.28 & 375 & $408 ; 446$ & 7,8 & 2 \\
\hline $\mathrm{O}_{2 c}(2 \mathrm{H}, 2 \mathrm{O})-1 \mathrm{a}$ & 0.28 & 372 & $446 ; 680$ & 8,8 & 2 \\
\hline $\mathrm{O}_{2 \mathrm{c}}(2 \mathrm{H}, 2 \mathrm{~S})-1 \mathrm{a}$ & 0.29 & 540 & $446 ; 945$ & 8,8 & 0 \\
\hline $\mathrm{O}_{2 \mathrm{c}}(1 \mathrm{~L}, 1 \mathrm{M})-1 \mathrm{a}$ & 0.85 & 731 & $900 ; 214$ & 6,4 & 0 \\
\hline $\mathrm{O}_{2 \mathrm{c}}(1 \mathrm{~L}, 1 \mathrm{R})-1 \mathrm{a}$ & 0.32 & 1509 & $900 ; 1134$ & 4,4 & 0 \\
\hline $\mathrm{O}_{2 \mathrm{c}}(1 \mathrm{~B}, 1 \mathrm{D})-1 \mathrm{a}$ & 1.87 & 522 & $214 ; 453$ & 5,6 & 0 \\
\hline $\mathrm{O}_{2 \mathrm{c}}(1 \mathrm{~B}, 1 \mathrm{D})-1 \mathrm{p}$ & 0.86 & 505 & $1212 ; 1275$ & 6,6 & 0 \\
\hline $\mathrm{O}_{3 \mathrm{c}}(1 \mathrm{~L}, 1 \mathrm{R})-1 \mathrm{o}$ & 1.75 & 1522 & $1437 ; 213$ & 3,4 & 0 \\
\hline$O_{3 c}(1 \mathrm{~A}, 1 \mathrm{G})-1 f$ & 1.92 & 429 & $242 ; 241$ & 5,5 & 2 \\
\hline $\mathrm{O}_{4 \mathrm{c}}(1 \mathrm{~L}, 1 \mathrm{R})-2 \mathrm{e}$ & 0.32 & 1509 & $752 ; 983$ & 4,4 & 0 \\
\hline$O_{4 c}(1 A, 1 B)-2 e$ & 0.64 & 419 & $232 ; 232$ & 5,5 & 1 \\
\hline$O_{4 c}(1 F, 2 H)-2 e$ & 0.36 & 400 & $232 ; 230$ & 6,7 & 1 \\
\hline $\mathrm{O}_{4 c}(2 \mathrm{H}, 2 \mathrm{O})-2 \mathrm{~h}$ & 0.79 & 395 & $233 ; 233$ & 8,8 & 1 \\
\hline $\mathrm{O}_{4 c}(2 \mathrm{H}, 2 \mathrm{O})-2 e$ & 0.27 & 372 & $232 ; 376$ & 8,9 & 2 \\
\hline $\mathrm{O}_{4 \mathrm{c}}(2 \mathrm{H}, 2 \mathrm{~S})-2 \mathrm{~h}$ & 0.98 & 537 & $233 ; 446$ & 8,8 & 0 \\
\hline$O_{4 c}(2 O, 2 Q)-2 l$ & 0.61 & 372 & $233 ; 229$ & 7,7 & 1 \\
\hline $\mathrm{O}_{4 c}(2 \mathrm{O}, 2 \mathrm{P})-2 \mathrm{l}$ & 0.98 & 537 & $233 ; 445$ & 8,7 & 0 \\
\hline $\mathrm{O}_{4 c}(2 \mathrm{O}, 2 \mathrm{~N})-2 \mathrm{~h}$ & 0.61 & 395 & $233 ; 229$ & 7,7 & 1 \\
\hline
\end{tabular}

${ }^{a}$ Positions of $\mathrm{Y}^{3+}$ cations as shown in Fig. 8. Structure names in italics indicate that the $\mathrm{Y}^{3+}$ cations are located in nearest-neighboring positions. ${ }^{b}$ Relative energy with respect to the most stable structure, i.e., $\mathrm{O}_{2 \mathrm{c}}(1 \mathrm{E}, 1 \mathrm{~K})-1 \mathrm{a} .{ }^{c}$ Distance between two nearest $\mathrm{Y}$ cations. ${ }^{d}$ Distances between $\mathrm{Y}$ cations and the $\mathrm{O}$ vacancy. ${ }^{e}$ Coordination numbers of $\mathrm{Y}^{3+}$ with respect to $\mathrm{O}$ atoms. ${ }^{f}$ Number of $\mathrm{O}$ atoms bound simultaneously to both $\mathrm{Y}^{3+}$ cations.

In a similar way to the abovementioned models of the ceria(111) surface and the smaller ceria nanoparticle, no clear dependence of the structural stability on the distances between two yttrium cations (blue squares in Fig. 2A) or the location of the dopant cations in surface or subsurface positions (blue squares in Fig. 2B) was found. We also examined conceivable correlations between the relative stability and other characteristics of the models - the influence of the calculated electrostatic potentials at the cerium centers substituted by yttrium and the oxygen centers that were removed (Fig. S5A-C, ESI $\dagger$ ) and the average number of oxygen centers surrounding two $\mathrm{Y}^{3+}$ cations (Fig. S5D, ESI $\dagger$ ). However, no obvious trends were found.

3.3.2 Oxygen vacancy in nanoparticles containing two yttrium ions. We modeled 17 structures (Table 8) in which an $\mathrm{O}$ vacancy was created in the three most stable $\mathrm{Ce}_{38} \mathrm{Y}_{2} \mathrm{O}_{79}$ structures that were found, i.e., $\mathrm{O}_{2 \mathrm{c}}(1 \mathrm{E}, 1 \mathrm{~K})-1 \mathrm{a}, \mathrm{O}_{2 \mathrm{c}}(2 \mathrm{H}, 2 \mathrm{O})-1 \mathrm{a}$, and $\mathrm{O}_{2 \mathrm{c}}(1 \mathrm{~F}, 2 \mathrm{H})-1 \mathrm{a}$, which feature different combinations of $\mathrm{Y}^{3+}$ cations: two surface, two subsurface and one surface and one subsurface, respectively. Not unexpectedly, it is most energetically favorable to create an $\mathrm{O}$ vacancy in a low-coordinated position in the small (100) facets. The most stable structure is $\mathrm{O}_{2 \mathrm{c}}((1 \mathrm{E}, 1 \mathrm{~K})-1 \mathrm{a})-1 \mathrm{c}$, which has two surface $\mathrm{Y}^{3+}$ cations and two $\mathrm{O}$

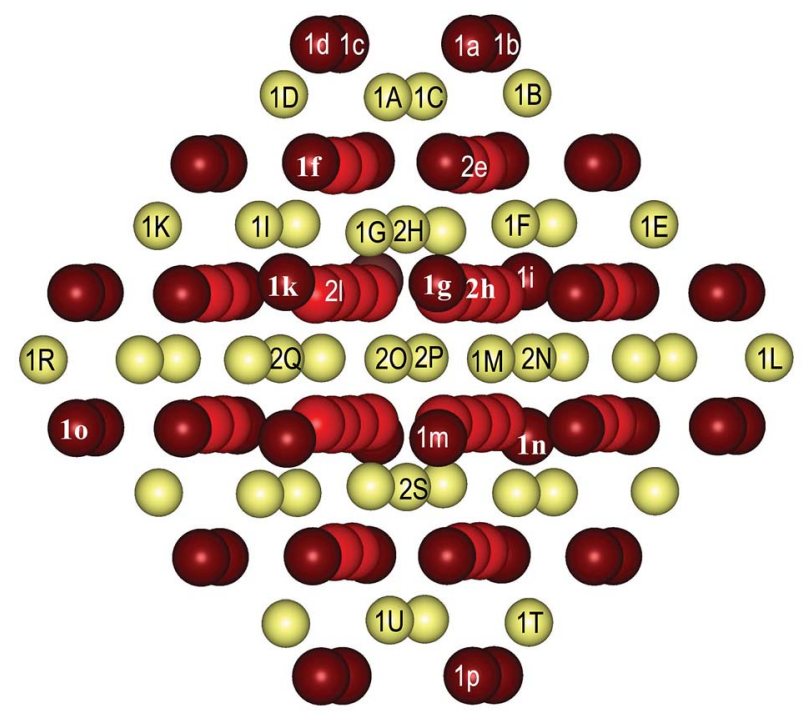

Fig. 8 Side view of $\mathrm{Ce}_{40} \mathrm{O}_{80}$ nanoparticle model. The positions of the cerium cations that are replaced by $\mathrm{Y}^{3+}$ ions are denoted by capital letters and numbers. The numbers indicate the positions of the $\mathrm{Ce}$ cations in the surface or subsurface shells. The created $O$ vacancy is denoted by a lower-case letter, and the number indicates whether the oxygen center is located in a surface (1) or a subsurface (2) position. Color coding: $\mathrm{Ce}$ - yellow, surface $\mathrm{O}$ centers - dark red, internal $\mathrm{O}$ centers - red.

vacancies at the two most distant low-coordinated sites of one (100) facet. It is less favorable to remove both $\mathrm{O}$ centers from neighbouring positions in a (100) facet: the corresponding structures $\mathrm{O}_{2 c}((1 \mathrm{E}, 1 \mathrm{~K})-1 \mathrm{a})-1 \mathrm{~b}$ and $\mathrm{O}_{2 \mathrm{c}}((1 \mathrm{E}, 1 \mathrm{~K})-1 \mathrm{a})-1 \mathrm{~d}$ are less stable by $0.65-0.66 \mathrm{eV}$ than the $\mathrm{O}_{2 \mathrm{c}}((1 \mathrm{E}, 1 \mathrm{~K})-1 \mathrm{a})-1 \mathrm{c}$ structure. When the second vacancy is created in another (100) facet opposite the first vacancy, the structure that is obtained, namely, $\mathrm{O}_{2 \mathrm{c}}((1 \mathrm{E}, 1 \mathrm{~K})-1 \mathrm{a})-1 \mathrm{p}$, is less stable by only $0.08 \mathrm{eV}$ than the most stable structure, i.e., $\mathrm{O}_{2 \mathrm{c}}((1 \mathrm{E}, 1 \mathrm{~K})-1 \mathrm{a})-1 \mathrm{c}$.

The lowest formation energy of an $\mathrm{O}$ vacancy in the latter structure is $0.9 \mathrm{eV}$, which is only slightly higher than the value calculated for the pristine $\mathrm{Ce}_{40} \mathrm{O}_{80}$ nanoparticle, namely, $0.8 \mathrm{eV} .^{28,29}$ The next most stable structure, namely, $\mathrm{O}_{2 \mathrm{c}}((2 \mathrm{H}, 2 \mathrm{O})-$ 1a)-1p, is characterized by the fact that both $\mathrm{Y}^{3+}$ cations are located in neighboring subsurface positions, whereas the positions of both oxygen vacancies are the same as in $\mathrm{O}_{2 \mathrm{c}}((1 \mathrm{E}, 1 \mathrm{~K})-1 \mathrm{a})-1 \mathrm{p}$. The former structure is less stable by only $0.06 \mathrm{eV}$ than the $\mathrm{O}_{2 \mathrm{c}}((1 \mathrm{E}, 1 \mathrm{~K})-1 \mathrm{a})-1 \mathrm{c}$ structure and has a similar formation energy of an $\mathrm{O}$ vacancy. The other structures that were considered are less stable by at least $c a$. $0.3 \mathrm{eV}$ than $\mathrm{O}_{2 \mathrm{c}}((1 \mathrm{E}, 1 \mathrm{~K})-1 \mathrm{a})-1 \mathrm{c}$.

In the $\left.\mathrm{O}_{2 \mathrm{c}}((1 \mathrm{E}, 1 \mathrm{~K}))-1 \mathrm{a}\right)-1 \mathrm{p}, \mathrm{O}_{2 \mathrm{c}}((2 \mathrm{H}, 2 \mathrm{O})-1 \mathrm{a})-1 \mathrm{k}, \mathrm{O}_{2 \mathrm{c}}((2 \mathrm{H}, 2 \mathrm{O})-$ 1a)-1p, $\mathrm{O}_{4 \mathrm{c}}((2 \mathrm{H}, 2 \mathrm{O})-1 \mathrm{a})-2 \mathrm{~h}, \mathrm{O}_{2 \mathrm{c}}((1 \mathrm{~F}, 2 \mathrm{H})-1 \mathrm{a})-1 \mathrm{p}$ and $\mathrm{O}_{2 \mathrm{c}}((1 \mathrm{~F}, 2 \mathrm{H})-$ 1a)-2e structures one of the $\mathrm{Ce}^{3+}$ cations is located next to the created $\mathrm{O}$ vacancy, whereas the other $\mathrm{Ce}^{3+}$ cation is far from the vacancy. In all the other structures that were considered both $\mathrm{Ce}^{3+}$ cations are in the vicinity of the created $\mathrm{O}$ vacancy.

3.3.3 Stoichiometric $\mathrm{Ce}_{40} \mathrm{O}_{80}$ nanoparticles containing four yttrium ions. We considered $23 \mathrm{Ce}_{36} \mathrm{Y}_{4} \mathrm{O}_{78}$ structures containing two pairs of $\mathrm{Y}^{3+}$ cations and two $\mathrm{O}$ vacancies (see Table 9). The 
Table 8 Energetic (in eV) and structural (in pm) characteristics of the modeled structures of the larger $\mathrm{Ce}_{40} \mathrm{O}_{80}$ nanoparticle containing two $\mathrm{Y}^{3+}$ cations and two $\mathrm{O}$ vacancies as well as of the pristine $\mathrm{Ce}_{40} \mathrm{O}_{80}$ nanoparticle

\begin{tabular}{|c|c|c|c|c|}
\hline Structure $^{a}$ & $E_{\text {rel }}^{b}$ & $E_{\mathrm{vac}}^{c}$ & $\mathrm{O}_{\mathrm{vac}}-\mathrm{O}_{\mathrm{vac}}{ }^{d}$ & $\# \mathrm{Ce}^{e}$ \\
\hline $\mathrm{CeO}_{2}-1 \mathrm{a}$ & & 0.76 & & 9,12 \\
\hline $\mathrm{CeO}_{2}-1 \mathrm{~b}$ & & 1.51 & & 2,3 \\
\hline $\mathrm{CeO}_{2}-1 \mathrm{c}$ & & 1.52 & & 3,4 \\
\hline $\mathrm{CeO}_{2}-1 \mathrm{~d}$ & & 1.53 & & 1,4 \\
\hline $\mathrm{CeO}_{2}-1 \mathrm{k}$ & & 1.60 & & 7,10 \\
\hline $\mathrm{CeO}_{2}-1 \mathrm{p}$ & & 1.53 & & 14,15 \\
\hline $\mathrm{CeO}_{2}-2 \mathrm{~h}$ & & 1.81 & & 5,12 \\
\hline $\mathrm{O}_{2 \mathrm{c}}((1 \mathrm{E}, 1 \mathrm{~K})-1 \mathrm{a})-1 \mathrm{~b}$ & 0.66 & 1.61 & 319 & 5,3 \\
\hline $\mathrm{O}_{2 \mathrm{c}}((1 \mathrm{E}, 1 \mathrm{~K})-1 \mathrm{a})-1 \mathrm{c}$ & 0.00 & 0.95 & 449 & 3,4 \\
\hline $\mathrm{O}_{2 \mathrm{c}}((1 \mathrm{E}, 1 \mathrm{~K})-1 \mathrm{a})-1 \mathrm{~d}$ & 0.65 & 1.60 & 315 & 1,4 \\
\hline $\mathrm{O}_{2 \mathrm{c}}((1 \mathrm{E}, 1 \mathrm{~K})-1 \mathrm{a})-1 \mathrm{k}$ & 0.40 & 1.35 & 765 & 7,10 \\
\hline $\mathrm{O}_{2 \mathrm{c}}((1 \mathrm{E}, 1 \mathrm{~K})-1 \mathrm{a})-1 \mathrm{p}$ & 0.08 & 1.03 & 1304 & 13,14 \\
\hline $\mathrm{O}_{2 \mathrm{c}}((2 \mathrm{H}, 2 \mathrm{O})-1 \mathrm{a})-1 \mathrm{~b}$ & 0.94 & 1.89 & 319 & 3,5 \\
\hline $\mathrm{O}_{2 \mathrm{c}}((2 \mathrm{H}, 2 \mathrm{O})-1 \mathrm{a})-1 \mathrm{c}$ & 0.36 & 1.31 & 449 & 3,8 \\
\hline $\mathrm{O}_{2 \mathrm{c}}((2 \mathrm{H}, 2 \mathrm{O})-1 \mathrm{a})-1 \mathrm{~d}$ & 0.99 & 1.94 & 315 & 1,8 \\
\hline $\mathrm{O}_{2 \mathrm{c}}((2 \mathrm{H}, 2 \mathrm{O})-1 \mathrm{a})-1 \mathrm{k}$ & 0.29 & 1.24 & 765 & 7,11 \\
\hline $\mathrm{O}_{2 \mathrm{c}}((2 \mathrm{H}, 2 \mathrm{O})-1 \mathrm{a})-1 \mathrm{p}$ & 0.06 & 1.01 & 1304 & 9,14 \\
\hline $\mathrm{O}_{4 \mathrm{c}}((2 \mathrm{H}, 2 \mathrm{O})-1 \mathrm{a})-2 \mathrm{~h}$ & 1.00 & 1.95 & 517 & 5,6 \\
\hline $\mathrm{O}_{2 \mathrm{c}}((1 \mathrm{~F}, 2 \mathrm{H})-1 \mathrm{a})-1 \mathrm{~b}$ & 0.92 & 1.87 & 319 & 2,3 \\
\hline $\mathrm{O}_{2 \mathrm{c}}((1 \mathrm{~F}, 2 \mathrm{H})-1 \mathrm{a})-1 \mathrm{c}$ & 0.40 & 1.35 & 449 & 3,8 \\
\hline $\mathrm{O}_{2 \mathrm{c}}((1 \mathrm{~F}, 2 \mathrm{H})-1 \mathrm{a})-1 \mathrm{~d}$ & 1.02 & 1.97 & 315 & 1,8 \\
\hline $\mathrm{O}_{2 \mathrm{c}}((1 \mathrm{~F}, 2 \mathrm{H})-1 \mathrm{a})-1 \mathrm{k}$ & 0.68 & 1.63 & 765 & 7,10 \\
\hline $\mathrm{O}_{2 \mathrm{c}}((1 \mathrm{~F}, 2 \mathrm{H})-1 \mathrm{a})-1 \mathrm{p}$ & 0.34 & 1.29 & 1304 & 13,14 \\
\hline $\mathrm{O}_{2 \mathrm{c}}((1 \mathrm{~F}, 2 \mathrm{H})-1 \mathrm{a})-2 \mathrm{e}$ & 1.50 & 2.45 & 255 & 2,5 \\
\hline
\end{tabular}

a The positions of $\mathrm{Y}^{3+}$ cations and removed $\mathrm{O}$ centers are shown in Fig. 8, whereas the numbers indicate whether the $\mathrm{Y}^{3+}$ cation or removed $O$ center is located in the surface region, 1 , or the subsurface region, 2. In parentheses is the structure with two $\mathrm{Y}^{3+}$ cations and one $\mathrm{O}_{\mathrm{vac}}$ from which the $\mathrm{O}$ center is removed. ${ }^{b}$ Relative energy with respect to the most stable structure, i.e., $\mathrm{O}_{2 \mathrm{c}}((1 \mathrm{E}, 1 \mathrm{~K})-1 \mathrm{a})-1 \mathrm{c}$. Formation energy of an $\mathrm{O}$ vacancy. ${ }^{d}$ Distance between two $\mathrm{O}$ vacancies. ${ }^{e}$ Positions of the $\mathrm{Ce}^{3+}$ cations (see numbers in Fig. S2).

most stable structure is $\mathrm{O}_{2 \mathrm{c}}(1 \mathrm{E}, 1 \mathrm{~K})-1 \mathrm{a} / \mathrm{O}_{2 \mathrm{c}}(2 \mathrm{H}, 2 \mathrm{~S})-1 \mathrm{p}$. Other structures that are built from two stable combinations of two $\mathrm{Y}^{3+}$ cations and one $\mathrm{O}$ vacancy also result in stable arrangements, such as $\mathrm{O}_{2 \mathrm{c}}(1 \mathrm{~L}, 1 \mathrm{R})-1 \mathrm{a} / \mathrm{O}_{2 \mathrm{c}}(2 \mathrm{H}, 2 \mathrm{~S})-1 \mathrm{p}, \mathrm{O}_{2 \mathrm{c}}(1 \mathrm{E}, 1 \mathrm{~K})-1 \mathrm{a} /$ $\mathrm{O}_{2 \mathrm{c}}(2 \mathrm{H}, 2 \mathrm{O})-1 \mathrm{p}$ and $\mathrm{O}_{2 \mathrm{c}}(2 \mathrm{H}, 2 \mathrm{O})-1 \mathrm{a} / \mathrm{O}_{2 \mathrm{c}}(1 \mathrm{~L}, 1 \mathrm{R})-1 \mathrm{p}$.

When both $\mathrm{O}$ centers are removed from one small (100) facet, it is not most favorable to remove them from two neighboring $\mathrm{O}$ sites. It is more favorable to remove two $\mathrm{O}$ centers that are located diagonally with respect to each other or are from two opposite (100) facets.

\section{Summary and conclusions}

We performed periodic density functional calculations on a $\mathrm{CeO}_{2}(111)$ slab as well as models of one smaller $\left(\mathrm{Ce}_{21} \mathrm{O}_{42}\right)$ and one larger $\left(\mathrm{Ce}_{40} \mathrm{O}_{80}\right)$ nanoparticle doped by two and four $\mathrm{Y}^{3+}$ cations. This substitution induces the formation of one and two $\mathrm{O}$ vacancies, respectively, for charge compensation.

\section{1 $\mathrm{CeO}_{2}(111)$ slab model}

The most stable structures on the $\mathrm{CeO}_{2}(111)$ surface are calculated to be those in which $\mathrm{Y}^{3+}$ cations are located at neighboring
Table 9 Energetic (in eV) and structural (in pm) characteristics of the structures of the larger $\mathrm{Ce}_{40} \mathrm{O}_{80}$ ceria nanoparticle containing four $\mathrm{Y}^{3+}$ cations and two $\mathrm{O}$ vacancies $\left(\mathrm{Ce}_{36} \mathrm{Y}_{4} \mathrm{O}_{78}\right)$

\begin{tabular}{|c|c|c|c|}
\hline Structure $^{a}$ & $E_{\text {rel }}^{b}$ & $\mathrm{Y}-\mathrm{Y}^{c}$ & $\Delta \mathrm{Y}-\mathrm{Y}^{d}$ \\
\hline $\mathrm{O}_{2 \mathrm{c}}(1 \mathrm{E}, 1 \mathrm{~K})-1 \mathrm{a} / \mathrm{O}_{2 \mathrm{c}}(1 \mathrm{~F}, 2 \mathrm{H})-1 \mathrm{p}$ & 0.34 & $1034 ; 369$ & 0 \\
\hline $\mathrm{O}_{2 \mathrm{c}}(1 \mathrm{E}, 1 \mathrm{~K})-1 \mathrm{a} / \mathrm{O}_{2 \mathrm{c}}(2 \mathrm{H}, 2 \mathrm{O})-1 \mathrm{p}$ & 0.21 & $1034 ; 371$ & 0 \\
\hline $\mathrm{O}_{2 \mathrm{c}}(1 \mathrm{E}, 1 \mathrm{~K})-1 \mathrm{a} / \mathrm{O}_{2 \mathrm{c}}(2 \mathrm{H}, 2 \mathrm{~S})-1 \mathrm{p}$ & 0.00 & $1034 ; 531$ & 0 \\
\hline $\mathrm{O}_{2 \mathrm{c}}(1 \mathrm{E}, 1 \mathrm{~K})-1 \mathrm{a} / \mathrm{O}_{2 \mathrm{c}}(1 \mathrm{~L}, 1 \mathrm{R})-1 \mathrm{p}$ & 0.38 & $1041 ; 1512$ & 7 \\
\hline $\mathrm{O}_{2 \mathrm{c}}(1 \mathrm{E}, 1 \mathrm{~K})-1 \mathrm{a} / \mathrm{O}_{2 \mathrm{c}}(1 \mathrm{~B}, 1 \mathrm{D})-1 \mathrm{p}$ & 1.17 & $1032 ; 529$ & -2 \\
\hline $\mathrm{O}_{2 c}(1 \mathrm{~F}, 2 \mathrm{H})-1 \mathrm{a} / \mathrm{O}_{2 \mathrm{c}}(1 \mathrm{~L}, 1 \mathrm{R})-1 \mathrm{p}$ & 0.36 & $372 ; 1512$ & -3 \\
\hline $\mathrm{O}_{2 \mathrm{c}}(1 \mathrm{~F}, 2 \mathrm{H})-1 \mathrm{a} / \mathrm{O}_{2 \mathrm{c}}(2 \mathrm{Q}, 2 \mathrm{~N})-1 \mathrm{p}$ & 0.28 & $372 ; 521$ & -3 \\
\hline$O_{2 c}(1 F, 2 H)-1 a / O_{2 c}(2 O, 2 N)-1 p$ & 0.52 & $367 ; 368$ & -8 \\
\hline $\mathrm{O}_{2 c}(1 \mathrm{~L}, 1 \mathrm{R})-1 \mathrm{a} / \mathrm{O}_{2 c}(2 \mathrm{H}, 2 \mathrm{~S})-1 p$ & 0.15 & $1512 ; 531$ & 3 \\
\hline $\mathrm{O}_{2 c}(2 \mathrm{H}, 2 \mathrm{O})-1 \mathrm{a} / \mathrm{O}_{2 c}(1 \mathrm{G}, 1 \mathrm{M})-1 \mathrm{~g}$ & 0.78 & $373 ; 412$ & 1 \\
\hline $\mathrm{O}_{2 c}(2 \mathrm{H}, 2 \mathrm{O})-1 \mathrm{a} / \mathrm{O}_{2 c}(1 \mathrm{~L}, 1 \mathrm{R})-1 \mathrm{p}$ & 0.29 & $372 ; 1512$ & 0 \\
\hline$O_{2 c}(2 H, 2 O)-1 a / O_{2 c}(1 L, 1 R)-1 b$ & 0.44 & $379 ; 1513$ & 7 \\
\hline $\mathrm{O}_{2 c}(2 \mathrm{H}, 2 \mathrm{O})-1 \mathrm{a} / \mathrm{O}_{2 c}(2 \mathrm{Q}, 2 \mathrm{~N})-1 c$ & 0.52 & $374 ; 518$ & 2 \\
\hline $\mathrm{O}_{2 c}(2 \mathrm{H}, 2 \mathrm{O})-1 \mathrm{a} / \mathrm{O}_{2 c}(2 \mathrm{Q}, 2 \mathrm{~N})-1 p$ & 0.32 & $368 ; 519$ & -4 \\
\hline $\mathrm{O}_{2 c}(2 \mathrm{H}, 2 \mathrm{O})-1 \mathrm{a} / \mathrm{O}_{2 c}(2 \mathrm{~S}, 2 \mathrm{P})-1 \mathrm{n}$ & 0.59 & $370 ; 370$ & -2 \\
\hline $\mathrm{O}_{2 c}(2 \mathrm{H}, 2 \mathrm{O})-1 \mathrm{a} / \mathrm{O}_{2 c}(2 \mathrm{~S}, 2 \mathrm{P})-1 \mathrm{p}$ & 0.51 & $373 ; 372$ & 1 \\
\hline$O_{2 c}(1 A, 1 G)-1 a / O_{2 c}(1 I, 1 F)-1 p$ & 1.95 & $351 ; 528$ & -18 \\
\hline$O_{2 c}(1 A, 1 B)-1 a / O_{2 c}(1 C, 1 D)-1 c$ & 1.30 & $422 ; 423$ & 3 \\
\hline$O_{2 c}(1 A, 1 B)-1 a / O_{2 c}(1 C, 1 D)-1 p$ & 3.23 & $418 ; 347$ & -1 \\
\hline $\mathrm{O}_{2 \mathrm{c}}(1 \mathrm{~A}, 1 \mathrm{~B})-1 \mathrm{a} / \mathrm{O}_{2 \mathrm{c}}(1 \mathrm{R}, 1 \mathrm{~L})-1 \mathrm{c}$ & 0.50 & $426 ; 1510$ & 7 \\
\hline $\mathrm{O}_{2 \mathrm{c}}(1 \mathrm{~A}, 1 \mathrm{~B})-1 \mathrm{a} / \mathrm{O}_{2 \mathrm{c}}(1 \mathrm{R}, 1 \mathrm{~L})-1 \mathrm{~d}$ & 1.24 & $420 ; 1510$ & 1 \\
\hline $\mathrm{O}_{2 \mathrm{c}}(1 \mathrm{~A}, 1 \mathrm{~B})-1 \mathrm{a} / \mathrm{O}_{2 \mathrm{c}}(1 \mathrm{R}, 1 \mathrm{~L})-1 \mathrm{p}$ & 0.80 & $418 ; 1510$ & -1 \\
\hline $\mathrm{O}_{2 \mathrm{c}}(1 \mathrm{~A}, 1 \mathrm{~B})-1 \mathrm{a} / \mathrm{O}_{2 \mathrm{c}}(1 \mathrm{U}, 1 \mathrm{~T})-1 \mathrm{p}$ & 1.14 & $417 ; 416$ & -2 \\
\hline
\end{tabular}

${ }^{a}$ The positions denoted by the corresponding letters are shown in Fig. 8 . Structure names in italics indicate that both $\mathrm{Y}^{3+}$ pairs are located close to each other. ${ }^{b}$ Relative energy with respect to the most stable structure, i.e., $\mathrm{O}_{2 \mathrm{c}}(1 \mathrm{E}, 1 \mathrm{~K})-1 \mathrm{a} / \mathrm{O}_{2 \mathrm{c}}(2 \mathrm{H}, 2 \mathrm{~S})-1 \mathrm{p} .{ }^{c}$ Distances between two nearest $\mathrm{Y}$ cations. $d$ Difference between the $\mathrm{Y}-\mathrm{Y}$ distances in the structure with two $\mathrm{Y}^{3+}$ cations $\left(\mathrm{O}_{4 \mathrm{c}}(2 \mathrm{I}, 1 \mathrm{H})-2 \mathrm{~h}: 399 \mathrm{pm}\right.$; $\mathrm{O}_{2 \mathrm{c}}(2 \mathrm{I}, 1 \mathrm{~A})-1 \mathrm{a}: 397 \mathrm{pm}$; and $\mathrm{O}_{2 \mathrm{c}}(1 \mathrm{~A}, 1 \mathrm{C})-$ 1a: $402 \mathrm{pm}$ ) and the structure with four $\mathrm{Y}^{3+}$ cations.

sites close to an oxygen vacancy created in the first or second subsurface layer.

The presence of $\mathrm{Y}^{3+}$ does not noticeably change the reducibility of the ceria slab model in the case of the most stable structures when the vacancy is in the first subsurface layer. However, when the oxygen vacancy is created in the surface or second subsurface layer, the formation energies of an $\mathrm{O}$ vacancy decrease by $0.2-0.3 \mathrm{eV}$ in the presence of $\mathrm{Y}^{3+}$ cations in comparison with the corresponding values calculated for the pristine ceria system. This result is important from a practical point of view, because yttrium can increase the mobility of surface oxygen centers and in this way facilitate the oxidation of adsorbates with their participation.

Our $\mathrm{CeO}_{2}(111)$ slab model with four $\mathrm{Y}^{3+}$ cations showed that there is no clear preference regarding whether both $\mathrm{Y}^{3+}$ pairs stay close to each other or separate. We also found that by combining two stable configurations of a $\mathrm{Y}^{3+}$ pair and an $\mathrm{O}$ vacancy one obtains a stable structure.

When the dopant ions are in the surface layer, the basicity of surface oxygen centers around the dopant ions is slightly higher than that of the corresponding $\mathrm{O}$ centers on the surface of pristine ceria, as estimated from the shifts in the $\mathrm{O} 1 \mathrm{~s}$ core level. In contrast, oxygen centers near the oxygen vacancy experience stabilization of their $\mathrm{O} 1 \mathrm{~s}$ levels, i.e., lower basicity. 


\subsection{Models of smaller $\mathrm{Ce}_{21} \mathrm{O}_{42}$ nanoparticle}

Our previous calculations showed that in pristine ceria nanoparticles of this kind $\mathrm{O}$ centers are most easily removed from low-(two-)coordinated sites. ${ }^{28,29}$ However, we were unable to confirm this observation in the case of the doped $\mathrm{Ce}_{19} \mathrm{Y}_{2} \mathrm{O}_{41}$ structures, in which one $\mathrm{O}$ center was removed for charge compensation upon the introduction of the two $\mathrm{Y}^{3+}$ cations. In the most stable structures containing yttrium dopants, oxygen centers are removed from the top two O layers: two-coordinated $O$ centers from the (100) facet and four-coordinated $O$ centers from the layer below. In contrast to the doped ceria slab models, in these models of ceria nanoparticle it does not seem to be obligatory that both $\mathrm{Y}^{3+}$ cations should be in neighboring positions near the $\mathrm{O}$ vacancy, which is probably due to the higher structural flexibility of the nanoparticles. Our calculations showed that in the most stable structures $\mathrm{Y}^{3+}$ cations replace $\mathrm{Ce}^{4+}$ cations from the (100) facet or the layers beneath it, including the only subsurface cation site.

\subsection{Models of larger $\mathrm{Ce}_{40} \mathrm{O}_{80}$ nanoparticle}

In the most stable structures $O$ vacancies are created in the small (100) facets, where O centers are low-(two-)coordinated. It is not favorable to remove four-coordinated $\mathrm{O}$ centers from subsurface regions. In the latter case the energy of the structure is high, or a surface O center moves to the subsurface vacancy during geometry optimization and fills it. $\mathrm{A} \mathrm{Y}^{3+}$ cation is stable when it replaces a $\mathrm{Ce}^{4+}$ cation in the same coordination environment; it is not necessary to remove an $\mathrm{O}$ center from around the $\mathrm{Y}^{3+}$ cation. The presence of $\mathrm{Y}^{3+}$ dopants can increase the formation energy of an $\mathrm{O}$ vacancy to an insignificant extent.

When four $\mathrm{Y}^{3+}$ cations are introduced into the nanoparticle it is not favorable that both $\mathrm{O}$ vacancies should be created in one (100) facet. In the most stable structures oxygen vacancies are located in different facets of the nanoparticle. Combinations of two stable positions of the $\mathrm{Y}^{3+}$ cations lead to a stable structure. There is no clear preference regarding whether $\mathrm{Y}^{3+}$ cations should be close to each other or well apart. This is also the case for the distance from $\mathrm{Y}^{3+}$ ions to $\mathrm{O}$ vacancies.

\subsection{General conclusions}

Our calculations demonstrate that the smaller is an yttriumdoped ceria system the fewer rules and trends can be elucidated regarding the energetic and structural features of the most stable locations of the dopant ions with respect to each other and to the created charge-compensating $\mathrm{O}$ vacancies. In the slab models one can observe some trends in the preferred locations of the $\mathrm{Y}^{3+}$ cations and the $\mathrm{O}$ vacancy. It is most stable when the $\mathrm{Y}^{3+}$ cations stay close to each other and the created $\mathrm{O}$ vacancy is in their immediate vicinity, both preferably in the subsurface region. In contrast, the smaller $\mathrm{Ce}_{21} \mathrm{O}_{42}$ nanoparticle, which has various exposed low-coordinated corner and edge sites and a very flexible structure, does not exhibit a clear tendency either for the locations of $\mathrm{Y}^{3+}$ cations or for the position of the $\mathrm{O}$ vacancy. A similar statement can be made for the results of computational modeling we obtained for the doped larger $\mathrm{Ce}_{40} \mathrm{O}_{80}$ nanoparticles. However, one trend was found in the latter case regarding the location of the $\mathrm{O}$ vacancies, which are preferentially formed on the small (100) facets, where less strongly bound two-coordinated $\mathrm{O}$ centers are available for removal.

In addition, we found that in the structures with four $\mathrm{Y}^{3+}$ cations and two $\mathrm{O}$ vacancies the most stable structures can be obtained by combining the positions in the most stable structures with two $\mathrm{Y}^{3+}$ cations and one $\mathrm{O}$ vacancy.

Hence, the main effect of yttrium doping on the ceria slab model, which is representative of large ceria particles, is the lowering of the formation energy of an oxygen vacancy for surface oxygen centers by $c a$. $0.3 \mathrm{eV}$, and it thus becomes almost the same as the energy required for the formation of a subsurface vacancy. In general, the doping of ceria with yttrium has a negligible effect on the reducibility of ceria surfaces and nanoparticles. One reason may be the very similar ionic radii of $\mathrm{Y}^{3+}$ and $\mathrm{Ce}^{4+}$ ions, which differ by only 0.03 and $0.05 \AA$ for 6 - and 8-coordinated ions, respectively. ${ }^{43}$

On the other hand, the lack of preference regarding the positions of yttrium cations and oxygen vacancies in the doped ceria nanoparticles, in combination with their flexibility, would facilitate local rearrangements between structures of similar stability. This may also be related to the migration of oxygen in these systems, which can enable the dedicated use of $\mathrm{CeO}_{2}-$ $\mathrm{Y}_{2} \mathrm{O}_{3}$ nanocomposites in catalytic applications.

\section{Conflicts of interest}

There are no conflicts to declare.

\section{Acknowledgements}

Support by the Bulgarian National Science Fund (project DN-09/ 5), the Horizon2020 program of the European Commission (project Materials Networking, grant agreement 692146), the European Regional Development Fund and the Operational Program "Science and Education for Smart Growth" under contract UNITe no. BG05M2OP001-1.001-0004-C01 (2018-2023) is gratefully acknowledged. HAA is grateful to the Operational Program "Science and Education for Smart Growth" project BG05M2OP001-2.009-0028. KMN acknowledges support by the Spanish MINECO-FEDER grant CTQ2015-64618-R and by the grant 2017SGR13 from the Generalitat de Catalunya. The authors thank the Red Española de Supercomputación for the computer resources and the technical support.

\section{References}

1 A. Trovarelli, Catal. Rev.: Sci. Eng., 1996, 38, 439-520.

2 Catalysis by Ceria and Related Materials, ed. A. Trovarelli, Imperial College Press, London, 2002.

3 Catalysis by Ceria and Related Materials, ed. A. Trovarelli and P. Fonasiero, 2nd edn, Imperial College Press, London, 2013.

4 J. Paier, C. Penschke and J. Sauer, Chem. Rev., 2013, 113, 3949-3985.

5 D. R. Mullins, Surf. Sci. Rep., 2015, 70, 42-85. 
6 T. Montini, M. Melchionna, M. Monai and P. Fornasiero, Chem. Rev., 2016, 116, 5987-6041.

7 P. Fornasiero and A. Trovarelli, Catal. Today, 2015, 253, 1218.

8 E. W. McFarland and H. Metiu, Chem. Rev., 2013, 113, 43914427.

9 S. M. Collins, S. Fernandez-Garcia, J. J. Calvino and P. A. Midgley, Sci. Rep., 2017, 7, 5406.

10 I. Atribak, A. Bueno-López and A. García-García, J. Mol. Catal. A: Chem., 2009, 300, 103-110.

11 Y. She, L. Li, Y. Zhan, X. Lin, Q. Zheng and K. Wei, J. Rare Earths, 2009, 27, 411-417.

12 L. Ilieva, P. Petrova, G. Pantaleo, R. Zanella, L. F. Liotta, V. Georgiev, S. Boghosian, Z. Kaszkur, J. W. Sobczak, W. Lisowski, A. M. Venezia and T. Tabakova, Appl. Catal., $B, 2016,188,154-168$.

13 E. O. Jardim, S. Rico-Francés, F. Coloma, E. V. RamosFernández, J. Silvestre-Albero and A. Sepúlveda-Escribano, Appl. Catal., A, 2014, 487, 119-129.

14 P. P. Dholabhai, J. B. Adams, P. Crozier and R. Sharma, J. Chem. Phys., 2010, 132, 094104.

15 P. P. Dholabhai, J. B. Adams, P. Crozier and R. Sharma, Phys. Chem. Chem. Phys., 2010, 12, 7904-7910.

16 M. Burbano, S. T. Norberg, S. Hull, S. G. Eriksson, D. Marrocchelli, P. A. Madden and G. W. Watson, Chem. Mater., 2012, 24, 222-229.

17 S. Grieshammer, B. O. H. Grope, J. Koettgen and M. Martin, Phys. Chem. Chem. Phys., 2014, 16, 9974-9986.

18 Z. Hu and H. Metiu, J. Phys. Chem. C, 2011, 115, 1789817909.

19 M. Nolan, J. Phys. Chem. C, 2011, 115, 6671-6681.

20 J. P. Perdew, J. A. Chevary, S. H. Vosko, K. A. Jackson, M. R. Pederson, D. J. Singh and C. Fiolhais, Phys. Rev. B: Condens. Matter Mater. Phys., 1992, 46, 6671-6687; ibid, 1993, 48, 4978.

21 G. Kresse and J. Hafner, Phys. Rev. B: Condens. Matter Mater. Phys., 1993, 47, 558-561.

22 Version VASP.5.3; http://cms.mpi.univie.ac.at/vasp/.

23 G. Kresse and D. Joubert, Phys. Rev. B: Condens. Matter Mater. Phys., 1999, 59, 1758-1775.

24 V. I. Anisimov, F. Aryasetiawan and A. I. Lichtenstein, J. Phys.: Condens. Matter, 1997, 9, 767-808.

25 S. L. Dudarev, G. A. Botton, S. Y. Savrasov, C. J. Humphreys and A. P. Sutton, Phys. Rev. B: Condens. Matter Mater. Phys., 1998, 57, 1505-1509.
26 C. Loschen, J. Carrasco, K. M. Neyman and F. Illas, Phys. Rev. B: Condens. Matter Mater. Phys., 2007, 75, 035115.

27 E. A. Kümmerle and G. Heger, J. Solid State Chem., 1999, 147, 485-500.

28 A. Migani, G. N. Vayssilov, S. T. Bromley, F. Illas and K. M. Neyman, Chem. Commun., 2010, 46, 5936-5938.

29 A. Migani, G. N. Vayssilov, S. T. Bromley, F. Illas and K. M. Neyman, J. Mater. Chem., 2010, 20, 10535-10546.

30 G. N. Vayssilov, Y. Lykhach, A. Migani, T. Staudt, G. P. Petrova, N. Tsud, T. Skála, A. Bruix, F. Illas, K. C. Prince, V. Matolín, K. M. Neyman and J. Libuda, Nat. Mater., 2011, 10, 310-315.

31 H. A. Aleksandrov, K. M. Neyman and G. N. Vayssilov, Phys. Chem. Chem. Phys., 2015, 17, 14551-14560.

32 H. A. Aleksandrov, K. M. Neyman, K. I. Hadjiivanov and G. N. Vayssilov, Phys. Chem. Chem. Phys., 2016, 18, 2210822121.

33 I. Z. Koleva, H. A. Aleksandrov and G. N. Vayssilov, Catal. Sci. Technol., 2017, 7, 734-742.

34 M. Y. Mihaylov, E. Z. Ivanova, H. A. Aleksandrov, P. St. Petkov, G. N. Vayssilov and K. I. Hadjiivanov, Mol. Catal., 2018, 451, 114-124.

35 A. Figueroba, A. Bruix, G. Kovács and K. M. Neyman, Phys. Chem. Chem. Phys., 2017, 19, 21729-21738.

36 Y. Lykhach, A. Bruix, S. Fabris, V. Potin, I. Matolínová, V. Matolín, J. Libuda and K. M. Neyman, Catal. Sci. Technol., 2017, 7, 4315-4345.

37 A. Bruix, Y. Lykhach, I. Matolínová, A. Neitzel, T. Skála, N. Tsud, M. Vorokhta, V. Stetsovych, K. Ševčíková, J. Mysliveček, R. Fiala, M. Václavů, K. C. Prince, S. Bruyère, V. Potin, F. Illas, V. Matolín, J. Libuda and K. M. Neyman, Angew. Chem., Int. Ed., 2014, 53, 10525-10530.

38 A. Figueroba, G. Kovács, A. Bruix and K. M. Neyman, Catal. Sci. Technol., 2016, 6, 6806-6813.

39 M. V. Ganduglia-Pirovano, J. L. F. Da Silva and J. Sauer, Phys. Rev. Lett., 2009, 102, 026101.

40 S. M. Kozlov and K. M. Neyman, Phys. Chem. Chem. Phys., 2014, 16, 7823-7829.

41 T. Tabakova, L. Ilieva, I. Ivanov, M. Manzoli, R. Zanella, P. Petrova and Z. Kaszkur, J. Rare Earths, 2018.

42 G. N. Vayssilov and N. Rösch, J. Catal., 1999, 186, 423-432.

43 WebElements, https://www.webelements.com, accessed September 2018. 